\title{
LOS PRECEDENTES FRANCESES Y ESTADOUNIDENSE Y SU INFLUENCIA EN LA RIGIDEZ CONSTITUCIONAL DE LA CONSTITUCIÓN ESPAÑOLA DE 1812
}

JOSÉ MANUEL VERA SANTOS 


\section{SUMARIO}

INTRODUCCIÓN. 1. LA RIGIDEZ CONSTITUCIONAL EN LA CONSTITUCIÓN DE ESTADOS UNIDOS DE AMÉRICA DEL NORTE DE 1787. 2. LA RIGIDEZ CONSTITUCIONAL EN EL CONSTITUCIONALISMO REVOLUCIONARIO FRANCÉS: 2.1. Constitución de 1791. 2.2. Constitución de 1793. 2.3. Constitución de 1795. 3. EL PROCEDIMIENTO DE REFORMA EN LA CONSTITUCIÓN DE 1812. CONCLUSIONES. 


\title{
LOS PRECEDENTES FRANCESES Y ESTADOUNIDENSE Y SU INFLUENCIA EN LA RIGIDEZ CONSTITUCIONAL DE LA CONSTITUCIÓN ESPAÑOLA DE $1812^{1}$
}

\author{
POR \\ JOSÉ MANUEL VERA SANTOS \\ Catedrático de Derecho Constitucional \\ Universidad Rey Juan Carlos
}

\section{INTRODUCCIÓN}

Cuando el Profesor Torres del Moral me indicó que era su intención realizar un número monográfico de la excelente Revista de Derecho Político referido a la Constitución de 1812, celebrando así su segundo centenario, decidí abordar, con su permiso, el tema que nos ocupa ${ }^{2}$. A lo largo de otros estudios ${ }^{3}$ ya observé que

\footnotetext{
${ }^{1}$ Este artículo se enmarca en el Proyecto de Investigación sufragado por la Junta de Comunidades de Castilla-La Mancha con referencia PII 1/09-0066-3787, referido a «La Constitución de 1812 y su influencia en América: orígenes y desarrollo del constitucionalismo español y latinoamericano».

2 Teóricamente podemos decir que la cuestión a estudiar forma parte de la «esencia» del actual Estado constitucional. Como podemos leer en la introducción de una de las obras señeras sobre la cuestión: «El Estado constitucional cimenta su estructura en dos pilares fundamentales: por un lado, en el principio político democrático; por otro, en el principio jurídico de supremacía constitucional (...) son las exigencias políticas, derivadas del principio democrático, y los requerimientos jurídicos, emanados del principio de supremacía constitucional, como medio de control del go-
} 
la misma «bebe» de netas influencias extranjeras (extranjerizantes, dirían algunos de sus padres constituyentes), lo cual tampoco es de extrañar, dado el momento histórico-político general y particular en aquella España que empezaba a desperezarse de su anquilosada forma de Estado y de gobierno, que suponía el régimen absolutista.

Respecto a la estructura del trabajo, abordaremos en primer término, y por razones no sólo cronológicas sino también metodológicas, el «sentir» norteamericano sobre la problemática del poder constituyente y la reforma constitucional, explicando las teorías en las que se sustenta y su reflejo en el Texto constitucional de 1787, aún hoy vigente. Posteriormente observaremos sus similitudes y diferencias con la aportación teórica francesa ${ }^{4}$ y su proyección en la realidad constitucional práctica, en el momento revolucionario (Constituciones de 1791, 1793 y 1795), textos que pudieron, o no, influir en la regulación que recoge la Constitución de 1812 y que estudiaremos a continuación, finalizando con las correspondientes conclusiones. Y todo ello, recogiendo la literalidad ${ }^{5}$ de los artículos referentes al procedimiento de reforma y los concordantes a los mismos; en el caso europeo además aludiré a los que afectan a la regulación de los poderes «políticos» por antonomasia, en este caso Monarca y Cortes, representantes de legitimidades en conflicto. No trato, pues, de realizar un estudio dogmático sobre

bernante, quienes condicionan la aparición del poder de reforma» (De Vega García, P. (1988) La reforma constitucional y la problemática del poder constituyente, Madrid, Tecnos, págs. 15 y 23).

3 En concreto, vid. el artículo publicado en el año 2006, en el número 66 de esta misma Revista «La influencia del constitucionalismo francés en la fase de iniciación constitucional española (1808-1834)» págs. 121-179. Con anterioridad publiqué en 2004 Las Constituciones de Francia, Valencia, Tirant lo Blanch, obra más genérica referida al constitucionalismo francés, en la que recojo, junto al estudio de los mismos, todos los textos constitucionales del país vecino, tanto en versión original como traducidos al español, además de los correspondientes cuadros sinópticos y una cronología histórico-constitucional.

${ }^{4}$ De «dos grandes modelos» nos habla De VeGa García (op. cit., págs. 29 y 30) indicando que para los americanos «el ejercicio del poder constituyente requiere siempre la participación directa del pueblo como efectivo titular de la soberanía. Por otra parte, se presenta la tesis sostenida por Sieyès, conforme a la cual se admite la delegación de competencias y se incorpora el principio representativo a la mecánica del poder constituyente». Vid. nota 18.

${ }^{5}$ He optado por acudir conjuntamente a las interpretaciones literal, lógica y sistemática, debido a que observo que existen ciertas cuestiones que se apartan, «perfilan» o matizan las opiniones generalmente más al uso, tanto en la doctrina francesa como, y sobre todo, española, inclusive las que yo he utilizado en obras generales como las citadas en la nota 3. Llegado el momento de estudiar en concreto esta temática y acudiendo a las fuentes primarias, esas matizaciones resultan ser lo suficientemente relevantes. De ahí que en este artículo también yo «matice» mis opiniones anteriores, sobre todo las referidas al procedimiento de reforma de la primera Constitución francesa en relación con la propia gaditana. 
la rigidez, la supremacía o la reforma constitucional. Simplemente voy a diseccionar el procedimiento de reforma establecido en cuatro textos constitucionales, enmarcados en su realidad jurídico-política con el fin de constatar, o no, la influencia que pudieran ejercer sobre los constituyentes de $1812^{6}$.

\section{LA RIGIDEZ CONSTITUCIONAL EN LA CONSTITUCIÓN DE ESTADOS UNIDOS DE AMÉRICA DEL NORTE DE 1787}

La tradición constitucional en las colonias americanas aparece mucho antes de su conformación estatal. Ya en 1620, las colonias americanas habían suscrito el Pacto de los Padres Peregrinos a bordo del «Flor de Mayo», primer ejemplo de los múltiples covenants que suscribieron los colonos americanos. La importancia de estos precedentes no es, en absoluto, desdeñable porque contenían el embrión del moderno concepto de poder constituyente, al ser ratificados directamente por los town-meetings o por el pueblo.

La idea de la creación del Estado como fruto del contrato social lleva aparejada que el pueblo «contratante» es el soberano; la siguiente derivada sería, en pura lógica, que este pueblo se dota de una Constitución que regula los aspectos básicos de su existencia comunitaria y que, la misma, tanto por su autoría, como por la temática objeto de regulación, debe gozar de supremacía respecto a la normativa ordinaria. De ahí que aparezca la institución de la enmienda, de la reforma constitucional, como instrumento básico que permite proteger dicha supremacía constitucional ${ }^{7}$.

${ }^{6}$ Dejo a un lado la posible influencia del pensamiento anglófilo, que la hubo. Me centro en modelos constitucionales rígidos, de ahí que tampoco aluda a alguno de los textos franceses coetáneos al nuestro de 1812: a partir de 1799 el constitucionalismo galo aboga, con los textos napoleónicos, por la flexibilidad constitucional (vid. nota 73), como ocurre con Gran Bretaña. Respecto a las influencias británicas pueden consultarse, entre otros, ArGÜELles, A. DE (1995) Discursos, Oviedo, Junta General del Principado de Asturias (Estudio preliminar de Francisco Tomás y Valiente), págs. XXV-XXXII; Moreno ALONso, M. (1989) «Sugerencias inglesas para unas Cortes españolas», en VV.AA. Materiales para el estudio de la Constitución de 1812, Madrid, Tecnos, págs. 499-520, o Varela Suanzes-Carpegna, J. (2007) Política y Constitución en España (18081978), Madrid, Centro de Estudios Políticos y Constitucionales, págs. 279 a 307, en un capítulo titulado «El debate sobre el sistema británico de gobierno en España durante el primer tercio del siglo XIX». En el propio Discurso Preliminar a la Constitución se alude al sistema inglés para argumentar sobre el mono o bicameralismo (SÁrZ DE VARANDA, R. (1957) Colección de leyes fundamentales, Zaragoza, Acribia, pág. 41.

7 De este modo, «la afirmación teórica y práctica del poder constituyente se produjo de manera espontánea, como algo que cae por su propio peso. El poder constituyente reside en el pue- 
Si en 1776 se declaró la independencia, en noviembre del año siguiente se aprobó la creación de una Confederación de Estados para la articulación de sus propias necesidades, sobre todo políticas y económicas. La realidad de la organización confederal evidenció numerosos problemas, destacando el de la ausencia de un verdadero poder ejecutivo. Ante esta situación, motivada por la disputa entre los Estados de Marylan y Virginia por los impuestos de navegación en el río Potomac, en febrero de 1787 se celebra una Convención de delegados de los Estados para proceder a la revisión de los Articles of Confederation. El resultado de los trabajos de la Convención de Filadelfia de 1787 fue, como sabemos, la elaboración de la Constitución de los Estados Unidos, gracias a la interpretación extensiva del mandato que le había conferido el Congreso de enmendar los viejos Articles».

Sin entrar en mayores consideraciones respecto a la organización institucional establecida hace ya más de dos siglos, respecto al tema que nos ocupa, se puede leer en el artículo V de la Constitución de 1787 que:

Siempre que las dos terceras partes de ambas Cámaras lo juzguen necesario, el Congreso propondrá enmiendas a esta Constitución, o bien, a solicitud de las legislaturas de los dos tercios de los distintos Estados, convocará una convención con el objeto de que proponga enmiendas, las cuales, en uno y otro caso, poseerán la misma validez que si fueran parte de esta Constitución, desde todos los puntos de vista y para cualesquiera fines, una vez que bayan sido ratificadas por las legislaturas de las tres cuartas partes de los Estados separadamente o por medio de convenciones reunidas en tres cuartos de los mismos, según que el Congreso haya propuesto uno u otro modo de hacer la ratificación, y a condición de que antes del año de mil ochocientos ocho no podrá hacerse ninguna enmienda que modifique en cualquier forma las cláusulas primera y cuarta de la sección novena del artículo primero y de que a ningún Estado se le privará, sin su consentimiento, de la igualdad de voto en el Senado.

Es decir, que este artículo $\mathrm{V}$ permite dos vías de iniciativa de reforma constitucional. A saber: a) el Congreso, con el acuerdo de dos tercios de los compo-

\footnotetext{
blo; el ejercicio práctico de ese poder constituyente se traduce en la Constitución; y la Constitución en cuanto producto del poder constituyente tiene que estar por encima de los poderes constituidos» (Pérez Royo, J. (1994) Curso de Derecho Constitucional, Valencia, Marcial Pons, págs. 81, 82 y 84). Y así se refleja en el Preámbulo de la Constitución de 1787: «Nosotros, el pueblo de los Estados Unidos... ordenamos y establecemos esta Constitución...». En La reforma de la Constitución. Madrid, Congreso de los Diputados, 1987, págs. 20 y 21, destaca que «el desarrollo de un procedimiento propio previsto en la Constitución para su reforma, tan evidente en nuestros días representaba a finales del siglo XVIII una novedad sorprendente, para la que apenas sí existían precedentes (...) reformas en la Constitución de manera pacífica, sin aplicación de la violencia, con ayuda de un procedimiento regulado, era algo nuevo».
} 
nentes de la Cámara de Representantes y del Senado, puede proponer y preparar enmiendas; y b) dos tercios de los Legislativos estatales pueden pedir al Congreso que, a este fin, reúna una Convención constitucional encargada de realizar dicha propuesta.

A continuación, el procedimiento necesita de la ratificación de este texto por el electorado de los Estados federados. Para dicha ratificación se articulan otras dos posibilidades entre las que el propio Congreso debe decidir: a) que las Legislaturas de las tres cuartas partes de los Estados ratifiquen las enmiendas que se sometan a su deliberación; b) que se reúnan Convenciones en los diferentes Estados. En este caso se necesita la ratificación de las tres cuartas partes de estas Convenciones ${ }^{8}$.

Teniendo en cuenta lo antes mencionado respecto a la iniciativa y a la postrera ratificación, podemos decir que el texto de 1787 preveía cuatro procedimientos diferentes para concluir la enmienda constitucional, bien que, en realidad, a lo largo de estos más de dos siglos, únicamente se ha seguido un procedimiento para enmendar la Constitución: la intervención combinada de mayorías cualificadas de los poderes legislativos «constituidos» de la Federación y de los Estados federados?.

Igualmente el procedimiento de reforma establece dos limitaciones a la misma. Así, y antes de $1808^{10}$ no podrían presentarse enmiendas referidas a las cláu-

${ }^{8}$ No obstante, «las iniciativas y las aprobaciones o ratificaciones son intercambiables, es decir, se puede dar una iniciativa por las dos terceras partes del Congreso federal que sea aprobada por las convenciones locales de tres cuartas partes de los Estados convocados al efecto» (CARBONELL, M. (2001) «Sobre la reforma constitucional y sus funciones», en MORODO, R. y DE VEGA GARCíA, P. (dirs.) Estudios de Teoría del Estado y Derecho Constitucional en honor de Pablo Lucas Verdú, t. II, México/Madrid, Instituto de Investigaciones Jurídicas. Universidad Nacional Autónoma de México/Servicio de Publicaciones de la Facultad de Derecho. Universidad Complutense de Madrid, pág. 861). Este «control» de los Estados federados en el procedimiento de enmienda se instituye, creo yo, para compensar una posible extralimitación de un Estado federal recién creado.

9 Pérez Royo, La reforma... op. cit., pág. 46. Esta participación combinada del Poder federal y de los Estados federados, exige matizar la obligada observancia de determinadas reglas. Así, corresponde al Congreso determinar si es necesaria una enmienda de la Constitución (aunque se admiten las sugerencias del Presidente); en caso de que se comience el proceso de enmienda, las Cámaras de los Estados federados actúan como órganos federales, bien que ellas pueden decidir el quórum por el que aprueban la enmienda. Si una Legislatura local rechazase inicialmente la enmienda no impide que, posteriormente y sin límite de tiempo, dicha enmienda pueda ser aprobada por los votos de los Estados. Ahora bien, si se ha prestado el consentimiento no podrá retirarse (se sigue la enumeración de CARBONELL, op. cit., pág. 862)

10 Es decir, veintiún años después de aprobada la Constitución. Fue ratificada por tres cuartas parte de Legislaturas/Convenciones de los Estados en junio de 1788, después de la adhesión de New Hampshire. 
sulas primera y cuarta de la sección novena del artículo primero ${ }^{11}$; además, como cláusula de intangibilidad, como límite material permanente, aparece la imposible reforma de la paridad de representación en el Senado de cada Estado federado.

Estamos, en definitiva, ante un procedimiento muy rígido. Tan es así que se ha aseverado que nos encontramos ante un procedimiento de «no reforma», de intangibilidad, con lo que ello conlleva en la práctica: la exclusión del procedimiento de reforma como garantía institucional necesaria para la adecuación de la Constitución a las necesidades de los tiempos ${ }^{12}$.

Se trata de un procedimiento de reforma muy cercano al «procedimiento de expedición original del Texto constitucional». Y, sin embargo, «no puede decirse que tal asamblea sea soberana, si se entiende por tal que la nación le haya concedido plenos poderes, porque esos poderes pueden ser limitados» ${ }^{13}$.

En definitiva, «el procedimiento resulta tan difícil, que jamás llegó a aplicarse con buen éxito, excepto en las materias de poca importancia (...) Es difícil dirigir los dos tercios de las dos asambleas y los tres cuartos de las cuarenta y cinco repúblicas, compuestas todas de dos asambleas, llamadas a dar su opinión y ponerse de acuerdo sobre la misma proposición. Salvo en el caso de una fuerte

11 La sección novena establecía determinados límites al Congreso. En concreto, dichos apartados establecían que «El Congreso no podrá prohibir antes del año mil ochocientos ocho la inmigración o importación de las personas que cualquiera de los Estados ahora existentes estime oportuno admitir, pero puede imponer sobre dicha importación una contribución o derecho que no exceda de 10 dólares por cada persona». Por su parte, la cláusula cuarta indicaba que «No se impondrá ningún impuesto directo ni de capitación, a nos ser que se establezca de forma proporcional al censo o recuento que antes se ordeno practicar». Respecto a lo primero, poco hay que explicar; en cuanto a esta última previsión, siguiendo lo que establece la sección segunda, indica que los impuestos directos se deben repartir en base a la población de cada Estado.

${ }^{12} \mathrm{Y}$ es que «de lo que se trata en realidad es de impedir la enmienda, de imposibilitar la reforma del texto constitucional, con lo cual obviamente no puede cumplir ese papel de garantía constitucional en sentido estricto en la medida en que, de hecho, queda fuera de las instituciones con las que se puede efectivamente operar en la práctica» (BISCARETTI DI RUFFIA, P. (1996) Introducción al Derecho Constitucional comparado. Las «formas de Estado» y las «formas de gobierno», Las Constituciones modernas, México, Fondo de Cultura Económica, pág. 549). Demasiada rotunda la aseveración: sí se han aprobado enmiendas de enjundia, aparte de que otras hayan quedado por el camino, opciones ambas que denotan el uso del procedimiento de enmienda.

13 BRYCE, J. (1987) La república norteamericana, Madrid, La España Moderna, tomo II, pág. 242. Es decir, nos encontramos ante un sistema «especialmente inidóneo para conseguir los objetivos que su propio tenor literal parecía poner de manifiesto [...] un procedimiento que está denunciado como inútil, dada su dificultad e, incluso, como antidemocrático, en la medida en que una minoría de la población podría frenar en el futuro las aspiraciones de reforma de la mayoría» (BLANCO VALDÉs, R. L. (1994) El valor de la Constitución. Separación de poderes, supremacía de la ley y control de constitucionalidad en los orígenes del Estado liberal, Madrid, Alianza Editorial, págs. 105, 106 y 107). 
presión de los sucesos y de las circunstancias que exigen medidas rápidas, tales como las que determinaron la misma aceptación de la Constitución de 1787». A ello, añádase que, además, necesita de un tiempo excesivamente largo para su ulterior ratificación ${ }^{14}$. Tal cúmulo de objeciones ha supuesto, como sabemos, la adopción de un sistema de «revisión judicial» de la Constitución.

\section{LA RIGIDEZ CONSTITUCIONAL EN EL CONSTITUCIONALISMO REVOLUCIONARIO FRANCÉS}

Las influencias políticas de lo acontecido en Estados Unidos llegan a Euro$\mathrm{pa}^{15}$, sobre todo a una Francia que las dotará de una universalidad de la que adolecían allende los mares. Por vez primera se aúna la legitimidad política y la jurídica ${ }^{16}$ bajo un racionalismo filosófico y político que permitirá identificar soberanía y poder constituyente ${ }^{17}$ como hacedor de una Constitución que goza de supremacía y que diferencia así tanto su obra como a su autor respecto de los poderes constituidos.

Hago mío este resumen clarificador del concepto de poder constituyente en la doctrina francesa: «de un lado, el poder constituyente ${ }^{18}$, desaparecido el Rey, se

14 Según Carbonell, op. cit., pág. 862. La enmienda veintisiete a la Constitución norteamericana fue inicialmente ratificada por algunos Estados en 1789, pero no reunió el resto de los votos hasta 1992. Discrepo sobre la «poca importancia» de las enmiendas aprobadas. Su mera lectura indica lo contrario. Cabe apostillar que se han aprobado veintisiete enmiendas en estos más de doscientos años, diez de ellas de las doce presentadas en septiembre de 1789 y que se ratificaron en diciembre de 1791 , constituyen lo que se conoce como «Carta de Derechos». Existen también varias enmiendas pendientes de ratificación (cuatro), junto a otras que han expirado por sus propios términos.

15 Resulta curiosa la polémica sobre la «paternidad» del concepto de poder constituyente como diferente y superior a los poderes constituidos, sobre si es una idea inspirada por el constitucionalismo americano, tal como defiende Lafayette, o por el francés revolucionario, como insiste Sieyès, quién se arroga la misma para sí. Vid. al respecto Pérez SERrano, N. (1984) Tratado de Derecho Político, Madrid, Civitas, pág. 463, o DE VEGA GARCía La reforma op. cit., pág. 27.

16 García Pelayo, M. (1999) Derecho Constitucional comparado, Madrid, Alianza editorial, pág. 331.

17 Tuve ocasión de resumir la vinculación entre poder constituyente, poder soberano y la relación del primero con la realidad social previa (ausencia de absolutismo en Estados Unidos, su presencia en Europa), en el capítulo correspondiente del manual colectivo en el que participé, hace ya años. Me refiero a Merino, Merchán, J. F., Pérez-Ugena Coromina, M. y Vera Santos, J. M. (1995) Lecciones de derecho constitucional, Madrid, Tecnos, págs. 93 a 95.

18 Sieyès ya había expresado su teoría sobre el concepto de poder constituyente en su conocido opúsculo ¿Qué es el Estado llano? Dice el gran hacedor de Constituciones, tanto revolucionarias como bonapartistas, que «en cada una de sus partes la Constitución no es obra del poder constituido sino del poder constituyente». Un poder constituyente que ubica en la Nación, compuesta 
encomienda a la Nación, de manera que la soberanía política se convierte así en soberanía jurídica. De otro, puesto que la Nación carece de existencia física y no puede actuar por sí misma, ejerce el poder constituyente a través de unos representantes extraordinarios. Finalmente el poder constituyente es un poder distinto de los otros clásicos poderes del Estado formulados por Montesquieu (legislativo, ejecutivo y judicial) cuya competencia propia consiste en dotar a un pueblo de una Constitución, debiendo abstenerse, en todo caso, de ejercitar otros poderes distintos» ${ }^{19}$. En consecuencia, «se dan bastantes similitudes de tipo formal entre cómo se plantea la cuestión a finales del XVIII en ambas orillas del Atlántico, sobre todo en lo que se refiere a la afirmación del poder constituyente como superior a los poderes constituidos y la intangibilidad de la Constitución para estos poderes constituidos» ${ }^{20}$.

No podemos olvidar que, por encima de esta teorización sobre el nacimiento de la doctrina de la soberanía nacional, flota una doble realidad teórica y práctica: la anterior soberanía absoluta del Monarca defendida por Hobbes y su plasmación fáctica en el mundo de los hechos. Va a ser la burguesía, clase revolucionaria hasta el siglo XIX, la que, apoyándose en las clases populares de las ciudades permitirá cambiar el carácter subjetivo de aquella soberanía a la que aludiese Bodino, para hacerla recaer en la Nación, permitiendo así un término medio en el que las clases burguesas pudieran acceder a la toma de decisiones políticas, contemporizando con la realeza, la nobleza y el clero ${ }^{21}$.

por un Tercer Estado al que cataloga como cuerpo vivo de la República y del que predica que es un «todo oprimido» que, siendo nada, quiere convertirse en protagonista (SIEYÈs, E.-J. (1998) ¿Qué es el Estado llano? (Precedido del ensayo sobre Los privilegios), Madrid, Centro de Estudios Constitucionales, págs. 107 y ss.)

19 De Esteban, J. y González-Trevijano, P. (1996) Curso de Derecho Constitucional español, Tomo III, Madrid, Universidad Complutense de Madrid, págs. 707 y 708. Esta última recomendación (la separación de funciones constituyentes y las constituidas), sin embargo, quebró en la posterior práctica constitucional francesa y española. Respeto a las bases en las que se sustenta el principio de soberanía nacional (mandato representativo, sufragio censitario, etc.) vid. Vera SANTOS, J. M. (1997) «La crisis del mandato representativo en el sistema electoral de listas: el transfuguismo político», en Studia Carande, Madrid, Centro de Estudios Superiores Sociales y Jurídicos Ramón Carande, págs. 131-160 [136-137].

${ }^{20}$ Pérez Royo, J. (1999) «De la reforma constitucional. Comentario introductorio al Título X», en Comentarios a la Constitución española de 1978, en Alzaga Villamil, O. (dir.) t. XII, Madrid, Edersa/Cortes Generales, pág. 492. En La reforma.... op. cit., págs. 43 y s. alude y concreta las mismas: la diferenciación entre poder constituyente y constituidos, la supremacía constitucional, su rigidez... Con ser esto cierto, han de recordarse también sus diferencias de origen y conceptúales, tal como destaco en nota 4 .

${ }^{21}$ Vid. un resumen sobre el concepto de soberanía en Merino, Pérez Ugena y Vera, op. cit., págs. 28 a 32 . 
De ahí que, de la convocatoria de los Estados Generales de 1789, surge la constitución de una Asamblea Nacional. Aparece así la Nación como sujeto de soberanía, una Nación entendida como elemento etéreo en su composición, que se proyecta desde el pasado hasta el futuro, y que conlleva que existan unos representantes de la misma ${ }^{22}$, componentes de dicha Asamblea, que serán los hacedores de la Constitución.

Paso a continuación a destacar la normativa en la que se consigna la rigidez constitucional en la Francia revolucionaria, en sus Textos de 1791, 1793 y 1795. Como ya he expuesto anteriormente en otros trabajos ${ }^{23}$, me refiero a la etapa del surgimiento del constitucionalismo en nuestro país vecino de la mano de los revolucionarios de 1789. Como después veremos al aludir al caso gaditano, en este primer momento, también en Francia, el mayor «enemigo» teórico y práctico de las nuevas ideas era el Monarca. De ahí que, en esta etapa, la finalidad del constitucionalismo continenta ${ }^{24}$ conlleva que la defensa de estas primeras Constituciones venga vinculada a sus valores, a sus principios; que sea una defensa «política» de la misma ${ }^{25}$. Esto explica que la defensa de la Constitución lo sea

22 «Puesto que una gran nación no puede reunirse toda ella en asamblea todas aquellas veces que lo exijan las circunstancias anormales, es preciso que ella confíe a unos representantes extraordinarios los poderes necesarios en estas ocasiones (...). Un cuerpo de representantes extraordinarios —explica Sieyès_- suple a la asamblea de toda la nación. No hay necesidad, sin duda, de que éstos hayan sido encargados de la plenitud de la voluntad nacional; basta con un poder especial cuando se trate de casos no frecuentes. Este cuerpo de representantes extraordinarios reemplaza a la nación en su independencia de todas las formas constitucionales. (...). De cualquier manera que hayan sido diputados, de cualquier forma que se reúnan y de cualquier forma que deliberen, siempre que no se ignore (y la nación no puede ignorarlo) que obran en virtud de un mandato extraordinario de los pueblos, su voluntad común valdrá tanto como la de la nación misma» (SIEYÈs, op. cit., págs. 111 a 113).

23 Vera SANTOS, Las Constituciones..., op. cit., 17 a 21 y La reforma constitucional... o c.,, págs. 64 a 74. Sigo a Roura Gómez, S. A. (1998), La defensa de la Constitución en la bistoria constitucional española. Rigidez y control de constitucionalidad en el constitucionalismo histórico español. Madrid, Centro de Estudios Políticos y Constitucionales, págs. 111 y ss., y a GonZÁlez Hernández, E. (2006) Breve historia del constitucionalismo común (1787-1931). Exilio político y «turismo constitucional», Madrid, Ramón Areces-Universidad Rey Juan Carlos, págs. 19 a 39. PÉREZ Royo (La reforma..., op. cit., págs. 41 y ss) alude a otra clasificación, bien que, a nuestros efectos, todas coinciden en la calificación de estos textos como los propios de la primera etapa constitucional francesa.

24 Recuérdese lo antes citado de que el modelo de Estados Unidos no seguía estos parámetros de enfrentamiento, produciéndose la asimilación de la soberanía popular sin mayor problema en una sociedad más igualitaria y muy lejana en sus postulados teóricos y prácticos de las del Viejo Continente.

25 De Vega García, P. (1984) «Supuestos políticos y criterios jurídicos en la defensa de la Constitución: algunas peculiaridades del ordenamiento constitucional español». Revista de Política Comparada, núm. 10-11, pág. 411. 
también de los principios del constitucionalismo, no de cómo implementarlos; de ahí que su posible reforma aparezca trufada de unos procedimientos extraordinariamente rigurosos.

Paso a destacar muy sucintamente los aspectos generales de cada Constitución ${ }^{26}$ para estudiar su procedimiento de reforma.

\subsection{La Constitución de 1791}

Ante la crisis política, social y económica que asolaba Francia a finales del siglo XVIII ${ }^{27}$, el Rey decide convocar Estados Generales. Así, en mayo de 1789 se produce la apertura de los mismos en Versalles, rompiendo con ciento setenta y cinco años ininterrumpidos sin convocatoria de una asamblea estamental que, imbuida ya de las ideas ilustradas, se constituye en Asamblea Nacional. Ya los mandatos de los representantes daban por hecho el carácter constituyente de la misma, al recoger, junto al mantenimiento de la Monarquía ${ }^{28}$, el establecimiento de derechos y libertades ${ }^{29}$ recogidos expresamente y que compondrían, junto a los principios de soberanía nacional y la separación de poderes, el nuevo orden francés.

Así pues, la Constitución francesa de 1791 presenta dos principios básicos, amén del reconocimiento de la Declaración de Derechos: el principio de sobera-

26 Para una mayor profundización en el periodo de iniciación del constitucionalismo galo, vid. Vera Santos, Las Constituciones..., op. cit., págs. 34 a 45. Los textos de 1789 (Declaración de Derechos del Hombre y del Ciudadano), 1791, 1793 y 1795 en págs. 49 a 186. Recojo una cronología histórico-política de esta época en las páginas 27 a 32.

27 Sobre dicha situación en la que se encontraba Francia tanto en el terreno de las ideas políticas (conceptos de ley o de nación, papel regio o aparición del tercer estado) y en el ámbito de la realidad social vid. MorabiTo, M. (2000) Histoire Constitutionnelle de la France (1789-1958), Paris, Montchrestien, págs. 13-47. De esta obra destacar igualmente la cronología con la que enmarca la postrer explicación de cada uno de los periodos que explica, una datación previa que facilita mucho el estudio y conocimiento de la tan compleja realidad constitucional gala. Desde el prisma de la historia política, vid. igualmente Bluche, F. (2001) Manuel d'bistoire politique de la France contemporaine, Paris: PUF, págs. 7-42. Destaca esta obra por sus cuadros sinópticos y mapas políticos.

28 Vid. en Hamon, F.; Troper, M. et Burdeau, G. (2001) Droit Constitutionnel, Paris, LGDJ, págs. 301-302. También Godechot, J. (1995) (Les Constitutions de la France depuis 1789, Paris, Garnier Flammarion, págs. 21-22). Tampoco en Cádiz se intenta traer la República, como resulta evidente.

29 Respecto a la aprobación, influencias recibidas, principios inspiradores y contenido de la Declaración de derechos del hombre y del ciudadano vid. VERA SANTOS Las Constituciones... op. cit., págs. 34 a 36. 
nía nacional y el de separación de poderes ${ }^{30}$. Respecto al primero (artículo 3 de la Declaración de Derechos y artículo 1 del Título II de la Constitución), pasa de residir en el Monarca absoluto (ahora, uno de los «representantes» de la Nación, junto a la Asamblea nacional legislativa «ex» artículo 2 del Título II) para, siguiendo a Sieyès, asentarse en la Nación.

En lo tocante a la separación de poderes, podemos definir este texto de 1791 como «obra de la desconfianza de un poder respecto a otro, de la asamblea respecto al Rey» ${ }^{31}$. El Monarca sigue siendo Jefe del Estado (art. 4, Título III); inviolable y sagrado, es denominado «Rey de los Franceses» (art. 2, Capítulo 2, Sección I, Título III) y, sobre todo, se encuentra sometido por vez primera al imperio de la ley (arts. 3 y ss.). Puede vetar los proyectos que presente el legislativo, en un plazo de dos meses, bien que si durante dos legislaturas sigue manteniéndose el proyecto, el Rey se encuentra obligado a sancionarlo (arts. 1 a 7, Sec. III, Cap. III, T. III). El Monarca no puede disolver el Cuerpo legislativo (art. 5, Cap. I, T. III). Sí elige y nombra a unos Ministros, incompatibles con el cargo parlamentario, que ya refrendan sus actos asumiendo la responsabilidad de los mismos (arts. 4, 5 y 6, Sec. IV, Cap. III, T. III).

La Asamblea nacional legislativa es unicameral. Compuesta de setecientos cuarenta y cinco miembros, con un periodo de mandato de dos años (art. 2, Cap. I, T. III), éstos resultaban elegidos por un sistema de sufragio censitario de doble grado, mediante el cual los «ciudadanos activos» ${ }^{32}$ nombran a unos «grandes

30 Principios básicos que se reiteran en el caso español, tal y como destaca VARELA SUANZESCARPegna, op. cit., pág. 13. También es cierto que no caben muchas otras opciones. Estamos ante el primer liberalismo con preeminencia de la soberanía nacional, radicada en la Asamblea. Se rompe con Hobbes y se aboga por Sieyès y Montesquieu. Rousseau vendrá más tarde.

31 Por la mayor parte de la doctrina vid. Debbasch, Ch. y Pontier, J.-M. (1996) Les Constitutions de la France, Paris, Dalloz, págs. 6-7. Otros tachan de «fracaso» esta separación de poderes tan estricta (PACTET, P. (1991) Institutions politiques. Droit constitutionnel, Paris, Masson, pág. 270).

32 La elección censitaria de doble grado partía de los conocidos como ciudadanos activos, que eran los que participan en las asambleas departamentales. Debían ser ciudadanos franceses, varones, mayores de 25 años y que pagasen un censo similar a tres días de trabajo por cuenta ajena. Habían de ser libres y tener cumplido el servicio militar (art. 2, Sec. II, Cap. I, T. III). El resto de los ciudadanos se conocen como «pasivos», pues gozan de los derechos reconocidos en la Declaración pero no participan en los asuntos públicos. De un total de veinticuatro millones de habitantes, serían ciudadanos activos en torno a cuatro millones y medio. Los ciudadanos activos participan a nivel departamental y, posteriormente, en un segundo estadio, en una cifra cercana al uno por ciento, constituyen la asamblea electoral, siendo elegibles un total aproximado de cuarenta mil personas que han de pagar un censo que va de cien a cuatrocientos jornales de trabajo. Para ser elegido representante en la Asamblea, sin embargo no se solicita censo alguno, por lo que parece se distingue entre electores y elegibles (arts. 2, 3 y 4, Sección II, Capítulo I, Título III) (LAVrofF, D. G. (1999) Le Droit Constitutionnel de la Vème République, Paris, Dalloz, pág. 24). 
electores» ${ }^{33}$, siendo estos últimos quienes eligen a los diputados. Dicha asamblea, que no puede ser en ningún caso disuelta por el Monarca (art. 5, Cap.I, T.III), además de discutir y aprobar leyes y presupuestos, goza de competencias financieras (emisión de moneda, fijación de tributos), administrativas (creación y supresión de los empleos públicos), penales (en juicios a los ministros y a aquellos que atenten contra la seguridad del Estado), diplomáticas (ratificación de tratados internacionales) y militares (declaración de guerra, reclutamiento) ${ }^{34}$.

El procedimiento de revisión prescrito por la Constitución de 1791 era extremadamente complicado, reflejando el deseo de la Asamblea nacional constituyente de hacer muy compleja la reforma. Se regulaba en el Título VII, «De la revisión de los decretos constitucionales». Literalmente, puede leerse:

Artículo primero.-La Asamblea nacional constituyente declara que la nación tiene el derecho imprescriptible de cambiar su Constitución; no obstante, considerando más conforme con el interés nacional el que se use de este derecho de revisión para cambiar, a través de los medios previstos en la propia Constitución, los artículos cuyos inconvenientes haya mostrado la experiencia, decreta que habrá de procederse por una Asamblea de revisión de la forma siguiente:

Artículo 2.-Cuando tres legislaturas consecutivas hayan expresado una voluntad uniforme para cambiar algún artículo constitucional, habrá lugar a la revisión solicitada.

Artículo 3.-La siguiente legislatura y la posterior no podrán proponer la revisión de ningún artículo constitucional.

Artículo 4.-De las tres legislaturas que podrán a continuación proponer algunos cambios, las dos primeras sólo se ocuparán de esta cuestión en los dos últimos meses de su último período de sesiones, y la tercera en el final de su primer período de sesiones anual o al comienzo del segundo.

Las deliberaciones sobre esta materia estarán sometidas a las mismas formas que los actos legislativos; pero los decretos mediante los cuales se exprese su voluntad no estarán sometidos a la sanción del Rey.

Artículo 5.-La cuarta legislatura, aumentada en doscientos cuarenta y nueve miembros elegidos en cada departamento doblando el número ordinario que es elegido en función de la población, se constituirá como Asamblea de revisión.

Estos doscientos cuarenta y nueve miembros serán elegidos cuando el nombramiento de los representantes del Cuerpo legislativo haya terminado, y de ello se hará un acta separada.

La Asamblea de revisión sólo estará compuesta de una cámara.

Artículo 6.-Los miembros de la tercera legislatura que haya solicitado el cambio no podrán ser elegidos para la Asamblea de revisión.

33 Se elige un gran elector por cada cien, ciento cincuenta y, sucesivamente, de cada doscientos cincuenta, según los ciudadanos activos que componían la asamblea, según se observa en el artículo 6, Sec. II, Cap. I, T. III.

34 Turpin, D. (1997) Droit Constitutionnel, Paris, PUF, pág. 279. 
Artículo 7.-Los miembros de la Asamblea de revisión, tras haber pronunciado juntos el juramento de vivir libres o morir, prestarán individualmente el de limitarse a decidir sobre las cuestiones les hayan sido sometidas por voluntad uniforme de las tres legislaturas precedentes; de guardar, además, con todas sus fuerzas la Constitución del reino, decretada por la Asamblea nacional constituyente los años de 1789, 1790 y 1791, y de ser en todo fieles a la nación, a la ley y al Rey.

Artículo 8.-La Asamblea de revisión estará obligada a continuación y sin más dilación a ocuparse de las materias sometidas a su examen: tan pronto como sus tareas hayan terminado, los doscientos cuarenta y nueve miembros suplementarios se retirarán sin poder tomar parte en ningún caso en los actos legislativos.

Vayamos por partes. En primer lugar, el artículo 1 proclama como principio general que «la nación tiene el derecho imprescriptible de cambiar su Constitución». Es decir, destaca el principio de soberanía nacional, bien que lo utiliza como excusa para aclarar que se considera «más conforme con el interés nacional» que se usen los medios previstos en la misma. La distinción entre el poder constituyente y el poder constituido de reforma constitucional toma cuerpo en la práctica constitucional francesa ${ }^{35}$. Y es que, de este artículo primero del Título VII y, a contrario sensu, del resto de los preceptos, también ha de destacarse que no se regula la reforma total (un poder constituyente, que por definición no permite límite jurídico alguno), sino la revisión parcial, siguiendo «los medios previstos en la propia Constitución» y únicamente respecto a aquellos «artículos cuyos inconvenientes haya mostrado la experiencia». Límites procedimentales, que a continuación veremos, y límites, podíamos decir, temporales, bien que indeterminados, en tanto se indica que será «la experiencia» el valor que guiará si debe reformarse o no la Constitución en alguno de sus aspectos.

Toda vez indicado que lo que se regula es la reforma parcial $^{36}$, se recoge en el artículo 2 su iniciativa: resulta que será la Asamblea nacional legislativa el úni-

35 Entre las disposiciones finales de esta Constitución podemos encontrar la siguiente: Ninguno de los poderes instituidos por la Constitución tiene derecho a cambiarla en todo o en parte, salvo las reformas que puedan realizarse por la vía de la revisión, de acuerdo con las disposiciones del título VII anterior. Obsérvese como se alude a los poderes constituidos y a su diferencia con el poder constituyente y su obra, la Constitución. En otra de dichas disposiciones se indica también expresamente cómo la «fidelidad» de los poderes constituidos a la obra constituyente queda «vigilada» por la Nación: La Asamblea nacional constituyente deja (a la Constitución) en manos de la fidelidad del Cuerpo legislativo, del Rey y de los jueces, a la vigilancia de los padres de familia, a las esposas y a las madres, a la afección de los ciudadanos jóvenes, $y$ al valor de todos los franceses. Bonitas palabras.

36 Parece que esta obviedad no llegó a nuestro constituyente de 1978 que, como sabemos, confunde la reforma total, que corresponde al poder constituyente, y la parcial. Vid. mi crítica al artículo 168 CE en Vera SANTOS, La reforma..., op. cit., págs. 235-239. También en el artículo con el que participo en el libro homenaje al Profesor Jorge de Esteban «Sobre el Título 
co órgano que podrá comenzar el proceso de reforma, excluyendo de ella al Rey ya desde este primer momento procesal ${ }^{37}$.

Pero dicha iniciativa, residiendo orgánicamente en el Legislativo unicameral, debe extenderse temporalmente durante tres legislaturas consecutivas. Lo que quiere decir que, en la práctica, el órgano legislativo ordinario debe ratificar, después de celebradas dos elecciones diferentes, la opinión sobre la reforma del artículo o los artículos constitucionales de manera «uniforme» ${ }^{38}$. Como según el artículo 2 del Capítulo Primero del Título III, cada legislatura dura dos años, nos encontramos con que la iniciativa para la reforma dura seis años. A partir de ese tiempo se procede a la constitución de la asamblea revisora, como veremos más tarde.

El artículo cuarto indica también unos límites temporales a la Asamblea nacional legislativa respecto del momento de la legislatura en la que debe proceder al estudio de una eventual reforma. Así, las dos primeras sólo pueden trabajar en esta cuestión en los dos postreros meses de su último periodo de sesiones ${ }^{39}$. La tercera podrá estudiar la iniciativa de reforma en el final de su primer periodo de sesiones anual o al comienzo del segundo ${ }^{40}$.

En cuanto al órgano y procedimiento referido a la iniciativa de reforma, el artículo tercero expresamente prohíbe que «la siguiente legislatura y la posterior» puedan proponer la revisión de algún artículo de la Constitución. Con ello se intenta establecer una «pausa» temporal respecto a la apertura de un nuevo periodo de reformas, una vez comenzado el anterior.

El apartado último del artículo cuarto nos reenvía al procedimiento legislativo ordinario como vía formal para la adopción de la decisión sobre la reforma ${ }^{41}$.

X de la Constitución española de 1978: de la reforma constitucional», obra que aún no ha visto la luz.

37 Como posteriormente veremos, tampoco puede el Rey vetar la reforma al no estar la misma sometida a sanción según indicaba el artículo 4. Ha de destacarse, no obstante, que, como también ocurre en el caso español en 1812, el Monarca podía presentar al Cuerpo Legislativo asuntos para que tomase en consideración su discusión (art. 1, Sección primera, Capítulo III, del Título III).

${ }^{38}$ Entiendo que es la primera legislatura la que expresa realmente el artículo o los artículos a reformar, prestando la segunda y la tercera su adhesión. No cabría, por tanto la posibilidad de que estas dos últimas Legislaturas introdujesen nuevos artículos o cambios: se conculcaría el espíritu de la norma. Lo mismo predicaré de la normación gaditana.

39 Se trata con ello que el Legislativo no deje de trabajar en sus tareas ordinarias para centrarse en la reforma. Se evitaría así una especie de «llamada al asambleísmo» que sería nociva para el desarrollo institucional prevenido en el Texto de 1789

${ }^{40}$ Queda así casi un año para que la nación, que va a volver a elegir a los miembros de la asamblea revisora, conozca las reformas propuestas.

${ }^{41}$ La Sección segunda, del Capítulo III, del Título III (arts. 1 a 11) establece el procedimiento 
Eso sí, expresamente excluye la necesaria sanción del Monarca para su entrada en vigor. Por tanto el Rey, ni en el momento de la iniciativa ${ }^{42}$, ni en el de la sanción, participa en el procedimiento de reforma; tampoco en su discusión. Se puede decir que, constitucionalmente, la soberanía nacional se ha impuesto a la regia.

Visto todo lo anterior, el artículo quinto pasa a regular el órgano específico de revisión, órgano híbrido, creado ad hoc para encargarse de aprobar la reforma, que va a estar compuesto por el Legislativo ordinario incrementado en doscientos cuarenta y nueve miembros más, no pudiendo formar parte del mismo aquellos miembros de la tercera legislatura (es decir, la que aprueba la iniciativa de reforma de manera definitiva para pasar a su aprobación), que hubiesen apoyado la iniciativa reformista ${ }^{43}$ (artículo 6). Un órgano unicameral con unos poderes de reforma limitados tanto material (indica el artículo siete que sus componentes deben «limitarse a decidir sobre las cuestiones que les hayan sido sometidas por voluntad uniforme de las tres legislaturas precedentes»), como temporalmente (por un lado el artículo ocho obliga a la asamblea revisora a ocuparse «sin dilación» de su tarea, además que, concluida ésta, se obliga a los doscientos cuarenta y nueve miembros suplementarios a retirarse). Concluiría así el procedimiento de reforma parcial, sin necesidad de sanción regia y tampoco sin que esta cuarta legislatura se extinga sino que sigue desarrollando poderes ordinarios.

Pues bien, la Constitución de 1791 estuvo en vigor durante menos de un año, lo que en la práctica significa que su vigencia efectiva fue nula. La aplicación regia del derecho de veto ${ }^{44}$ produjo gravísimos enfrentamiento de Luis XVI con la Asamblea. Podemos expresar gráficamente que «el 10 de agosto [de 1792] cuando la muchedumbre invade las Tullerías, donde reside la familia

deliberatorio del Cuerpo Legislativo. En resumen, se deben hacer tres lecturas del proyecto con un intervalo entre ellas de ocho días. Si se rechazase no se puede presentar en ese periodo de sesiones. La sanción regia (art. 10) será negada si el decreto aprobado no indica las fechas de las sesiones en las que se han celebrado las tres lecturas (art. 9). Los ocho artículos de la siguiente Sección regulan la sanción real.

42 Vid. nota 37.

43 Denota las «pocas ganas» de que la reforma se culmine. Si se hubiese negado la presencia de cualquiera de los miembros de la tercera legislatura alegando que así no se producirían reiteraciones argumentales y se reposarían las posiciones teóricas..., pero la negación de «los unos», de los que apoyan la reforma, y no de los que se oponen, deja mucho que desear. Como luego veremos (vid. nota 67), en 1795 se impide la presencia en el órgano de todos los componentes del Cuerpo legislativo que previamente discute las enmiendas.

44 Vid. Guillenchmidt, M. De (2000) Histoire Constitutionnelle de la France depuis 1789, Paris, Economica, pág. 14, aludiendo al bloqueo institucional producido por el uso del derecho de veto regio y los casos concretos. Esta obra es recomendable por el cuantioso número de aclaraciones terminológicas y biográficas, así como históricas y políticas que recoge. 
real, supone el fracaso del intento de maridaje entre la monarquía y la revolución. La Monarquía termina y con ella la Constitución de 1789» ${ }^{45}$. Por tanto, el procedimiento de reforma sucumbió ante el cambio «de» Constitución, situación política que no admite regulación. La Asamblea legislativa convoca una nueva asamblea que, siguiendo el modelo americano toma el nombre de Convención, recibiendo el encargo de dotar a Francia de un nuevo texto constitucional que, por cierto, nunca entraría en vigor.

\subsection{La Constitución de 1793}

En septiembre de 1792 la Convención decreta abolida la Monarquía, proclamando la República. El Texto del año I republicano, de 24 de junio de 1793, destaca su intento de conjugar los principios de libertad y de igualdad ${ }^{46}$. Organizativamente todo el sistema se basaría en el principio de soberanía popular ${ }^{47}$, reconocida expresamente en el artículo 25 . Y con ella aparece el sufragio universal (art. 29) e incluso la introducción de instituciones de democracia semidirecta como la consulta popular anterior a la aprobación de una norma de rango legal (art. 59).

El Cuerpo legislativo es, nuevamente, unicameral (art. 39), propone las leyes y aprueba los decretos (art. 53). Como ya he escrito, las leyes, para su definitiva aprobación, deben ser propuestas a consulta popular. Se va a considerar implícito el apoyo del pueblo a las mismas, salvo reclamación expresa de la mitad mas uno de los departamentos, en los que una décima parte de las asambleas primarias $^{48}$ debe reclamar en un plazo de cuarenta días posteriores a la recepción del

45 Debbasch y Pontier, op. cit., pág. 8.

46 Habla Morabito (op. cit., págs. 96-99) de «Constitución democrática», por su pronunciado acento social y su contenido ético; de «democracia generosa» en el ámbito electivo y en la presencia de instituciones de democracia semidirecta; y de «democracia autoritaria», en tanto se produce un absoluto predominio del Cuerpo legislativo. Con DeBbasch y PonTier (op. cit., pág. 42), destacamos que este texto recoge el principio de igualdad (art. 3) y su proyección en el orden político (arts. 20 y 29) y en el civil, prohibiendo la esclavitud y la servidumbre (art. 18). Aparecen los primeros derechos de naturaleza prestacional: es ahora el Estado quién debe hacer posible el derecho al trabajo, a la asistencia sanitaria o a la educación pública (arts. 21 ó 22). La Convención es la primera asamblea elegida por sufragio universal, ya que la Asamblea legislativa modificó las normas electorales fijadas en 1791, suprimiendo la diferenciación entre ciudadanos activos y pasivos.

47 Con Hamon, Troper y Burdeau (op. cit., pág. 314), podemos decir que nos encontramos ante una Constitución «según Rousseau». Turpin (op. cit., pág. 282) refleja que «después de Montesquieu [refiriéndose al texto de 1791] Rousseau».

48 Unas asambleas primarias que constituyen la organización del pueblo francés para «el uso de su soberanía», leemos en el artículo 2. Estas asambleas serán también las protagonistas en el pro- 
texto de la ley propuesta (arts. 56-60). El mandato de los miembros del Cuerpo legislativo es de un año (art. 40), plazo muy breve, siguiendo la doctrina de la democracia directa, para impedir la desafección entre mandantes y mandatarios. Se elige un diputado en razón de cada cuarenta mil individuos (art. 22) a través de las reuniones de las asambleas primarias (art. 23).

El Consejo ejecutivo se presenta como un poder muy debilitado, atendiendo tanto a su elevado número de componentes (veinticuatro, según establece el artículo 62), a su origen parlamentario (es el Cuerpo legislativo el que los elige de entre los propuestos por cada una de las ochenta y cinco asambleas electorales departamentales, según indican los artículos 63 y 64) y, en tercer lugar, a sus reducidas competencias, generalmente vinculadas al desarrollo meramente ejecutivo de decisiones del legislador ${ }^{49}$. Se procede a su renovación por mitades cada legislatura (art. 64).

Nos encontramos así ante un sistema asambleario, en el que el Consejo ejecutivo se encontraba absolutamente subordinado a una cámara legislativa también inestable.

Los artículos 115 a 117 de la Constitución del Año I, bajo el Título «De las Convenciones Nacionales», regulan no el proceso de reforma, si no la creación del órgano revisor. Ya lo decíamos antes: poco Sieyès, mucho Rousseau ${ }^{50}$. Los preceptos antes citados prescriben breves cuestiones al respecto. Así:

Artículo 115.-«Si en la mitad más uno de los departamentos, la décima parte de las asambleas primarias de cada uno de ellos, regularmente constituidas, solicita la revisión del

cedimiento de reforma al ser los sujetos competentes para iniciar la misma. Están compuestas por los ciudadanos domiciliados seis meses en el cantón, en un número que oscila entre doscientos y seiscientos, leemos en los artículos 11 y 12 .

49 De «agente de la asamblea» le tachan Hamon, Troper y Burdeau (op. cit., pág. 314). Estos autores destacan igualmente la imposibilidad del ejecutivo de poder vetar las leyes, disolver el legislativo o gozar de iniciativa legislativa.

50 Respecto a la teorización de Rousseau sobre la soberanía popular y su modelo de democracia directa he vertido mis opiniones, en este caso vinculadas al marco teórico de la democracia electrónica en mi artículo «Democracia y e-democracia» (2008), en Ríos Insúa, D. (coord.) Democracia electrónica, Madrid, LID, págs. 40 a 42. También en Merino, Pérez Ugena y Vera (op. cit., págs. 30 a 31 y 46 a 48). Brevemente podemos concluir que el ginebrino considera que la soberanía no pertenece a la Nación sino al pueblo, entendido como elemento personal actualizado, lo que permite que ese pueblo pueda ejercitar su soberanía de manera directa. Parece una lógica deducción después de que abogue por una vertebración democrática en virtud de la cual no debería delegarse el poder legislativo y, si así se hiciese, el mandato de los representantes debería ser imperativo y posteriormente aprobadas sus leyes por el cuerpo electoral. Ni que decir tiene que la realización del poder constituyente debe cumplir dichos parámetros con más razón. Y así se estatuye en la Constitución del año I. 
acta constitucional o la modificación de algunos de sus artículos, el Cuerpo legislativo está obligado a convocar a todas las asambleas primarias de la República para saber si ha lugar a una convención nacional».

Artículo 116.- "La convención nacional se constituye de la misma forma que las legislaturas y reúne todos sus poderes».

Artículo 117.-«En lo que respecta a la Constitución, sólo se ocupa de las materias que han motivado su convocatoria».

Así pues, la iniciativa para poder reformar, bien total, bien parcialmente la Constitución ${ }^{51}$, corresponde a una décima parte de las asambleas primarias de la mitad mas uno de los departamentos franceses. Una vez aprobada «desde abajo», el Cuerpo legislativo debe convocar a todas las asambleas primarias que se pronuncian, según su ordinario procedimiento ${ }^{52}$, sobre si ha lugar a convocar una Convención nacional.

Por tanto, si bien el comienzo de la iniciativa de reforma corresponde a una décima parte de las asambleas primarias de la mitad mas uno de los departamentos $^{53}$, hablando con propiedad, la fase iniciática no concluye con éxito hasta que todas las asambleas primarias, todo el pueblo, se pronuncia directamente al respecto, pasando, si así se acuerda, a la fase de constitución del órgano revisor.

Un órgano revisor, segunda fase del proceso, que se constituye de manera idéntica a la prevista para el legislador ordinario ${ }^{54}$, bien que «reúne todos sus poderes», por lo que, además del poder de reformar la Constitución, también gozaba del poder legislativo ${ }^{55}$. Eso sí, existe una limitación material respecto a los temas a tratar a la hora de proceder a la reforma, ya que el artículo 117 expresa que la Convención «sólo se ocupará de las materias que han motivado su convocatoria», no pudiendo por tanto, entrar en la modificación de otras cuestiones

51 La interpretación literal no ofrece dudas, al aludir a «la revisión del acta constitucional o la modificación de alguno de sus artículos». Vid. nota 36.

52 Vid. arts. 11 a 20.

53 Obsérvese que con esa alusión a los departamentos (provincias) franceses, lo que se logra es que el factor territorial se añada al poblacional y equilibre así al mismo.

54 Godechot, J. (1951) Les institutions de la France sous la Révolution et l'Empire, Paris, PUF, pág. 251. Se trataba de una elección por sufragio universal directo de las asambleas primarias que congregasen una población de treinta y nueve a cuarenta y una mil almas (art. 23).

55 Deslandres, M. (1932) Histoire constitutionnelle de la France de 1789 a 1870. De la fin de l'ancien regime a la chute de l'empire (1789-1815), Paris, Libraire Armand Colin/ Libraire du Recueil Sirey, pág. 289. Esta Convención acumulaba prácticamente todos los poderes (VERPEAUX, M. (1991) «Le droit parlementaire sous la Convention: traditions et particularités», Revue Française du Droit Constitutionnel, núm. 7, pág. 404). De nuevo vemos cómo la teoría de Sieyès que citábamos queda en entredicho. 
que las indicadas previamente en los acuerdos de las asambleas primarias, salvo que la reforma sea total, claro está.

Cabe la duda sobre si el pueblo debería pronunciarse posteriormente sobre la reforma aprobada por la Convención. Una interpretación sistemática me lleva a afirmarlo, y no ya por la propia conformación de esta Constitución como evidentemente rousseauniana: los artículos 56 a 60 regulan la elaboración de la ley y concretamente el artículo 59 expresa que «si pasados cuarenta días desde el envío de la ley propuesta (aprobada por el Cuerpo legislativo), en la mitad de los departamentos más uno, un décimo de las asambleas primarias de cada uno de ellos (...) no ha presentado reclamación, el proyecto será aceptado y se convertirá en ley» Por su parte, el artículo 60 indica que «si hay reclamación, el Cuerpo legislativo convocará a las asambleas primarias».

Parece seguir la lógica de la propia Constitución afirmar que la reforma, preparada por una Convención elegida de la misma manera que el Cuerpo legislativo ordinario, sea también sometida al menos a los mismos requisitos para su aprobación y entrada en vigor definitiva que cualquiera de las normas con rango legal.

\subsection{La Constitución de 1795}

Ante un devenir constitucional, político y social, no demasiado ejemplari$z^{2}{ }^{56} e^{56}$, los franceses van a intentar con la Constitución del año III, unir el principio de soberanía popular (art. 17) con una separación de poderes que frenara el asamblearismo anterior, instituyendo el bicameralismo (art. 44) por vez primera en Francia y potenciando los poderes del ejecutivo. Es el texto más extenso de todo el constitucionalismo francés y primero de los que, realizados por la Convención, entra en vigor ${ }^{57}$.

56 Como ya indiqué, la Constitución de 1793 no entró nunca en vigor. Ante la invasión del territorio y las revueltas interiores, el 10 de octubre de 1793 la propia Convención decide ser ella misma el único centro de toma de decisiones y de gobierno, dotando de amplios poderes al Comité de Salud Pública con el que Robespierre protagonizará una etapa conocida como la del Terror. Posteriormente el constituyente optará por un texto más moderado, aprobando la Constitución de 1795.

57 Son trescientos setenta y siete artículos a los que ha de añadirse treinta y uno que conforman la parte de derechos y deberes. "Constitución del miedo», la denomina Gallote, la realizada por revolucionarios moderados pero regicidas, como señala TURPIN (op. cit., pág 284). «Pintoresca» es como la califican Debbasch, CH.; Pontier, J.-M.; Bourdon, J. y Ricci, J. Cl. (1990) Droit Constitutionnel et institutions politiques. Paris, Economica, pág. 428, refiriéndose sin duda a la articulación de poderes prevista. Esta Constitución fue ratificada mediante referéndum que se celebró el 6 de septiembre. 
Tanto el Consejo de los Quinientos como el de Ancianos, que así se denominan las dos Cámaras legislativas, resultan elegidos por sufragio universal indirecto ${ }^{58}$; son cámaras permanentes y renovables por tercios anualmente (art. 53). El Consejo de los Quinientos (arts. 73 a 81) goza de iniciativa legislativa, debate y aprueba las leyes, debiendo sus miembros tener cumplidos los treinta años; el Consejo de los Ancianos (arts. 82 a 109) las ratifica o las reprueba en bloque ${ }^{59}$, estando compuesta por doscientos cincuenta miembros, mayores de cuarenta años, casados o viudos (arts. 82 y 83).

Entre el poder ejecutivo y las cámaras no existen elementos que permitan una relación recíproca entre ellos, de tal forma que el Directorio, formado por cinco miembros elegidos por el legislativo, no puede ni convocar ni disolver los Consejos, ni éstos obligar a la dimisión a los miembros del Directorio o a los ministros.

La Constitución de 1795 regulaba el procedimiento de reforma constitucional en los artículos 336 a $350^{60}$ :

Artículo 336.-Si la experiencia encontrase inconvenientes en algunos artículos de la Constitución, el Consejo de Ancianos propondría su revisión.

Artículo 337.-La propuesta del Consejo de Ancianos está, en este caso, sometida a la ratificación del Consejo de los Quinientos.

Artículo 338.-Cuando, en un período de nueve años, la propuesta del Consejo de Ancianos ratificada por el Consejo de los Quinientos, se haya elevado en tres épocas separadas una de otra al menos tres años, se convoca una asamblea de revisión.

58 La Constitución de 1795 retorna a un sistema electoral censitario muy similar al expresado en 1791. Así, para actuar como decisor en las cuestiones políticas, el ciudadano debe pagar una contribución que se establece valorando propiedades y sueldo. Ser ciudadano francés y vivir durante un año en el cantón son las condiciones que dan derecho a participar como miembro de la asamblea primaria; para hacerlo en la asamblea electoral se requiere ser mayor de veinticinco años y ser propietario, arrendatario o usufructuario de bienes por un valor que varía entre cien y cuatrocientos jornales (arts. 8 a 40).

59 En palabras de LAVroff (op. cit., pág. 28) «los primeros son la imaginación y la voluntad de la República, los segundos la razón».

${ }^{60}$ Paso a nota a pie de página los preceptos menos relevantes a nuestros efectos: Artículo 340.-El Consejo de Ancianos designa, para la reunión de la asamblea de revisión un lugar que diste al menos 20 miriámetros del lugar donde está la sede del Cuerpo legislativo. Artículo 341.-La asamblea de revisión tiene el derecho de cambiar el lugar de su residencia observando la distancia prescrita por el artículo anterior.(...) Artículo 344.-Los miembros de la asamblea de revisión deliberan en común (...). Artículo 348. - Los miembros de la asamblea de revisión no pueden ser investigados ni acusados ni juzgados en ningún momento por algo que hayan dicho o escrito en el ejercicio de sus funciones. Mientras duren esas funciones, sólo pueden ser enjuiciados por una decisión de los mismos miembros de la asamblea de revisión. Artículo 349.-La asamblea de revisión no asistirá a ninguna ceremonia pública; sus miembros reciben la misma remuneración que la de los miembros del Cuerpo legislativo. Artículo 350.-La asamblea de revisión tiene el derecho de mantener o hacer mantener el orden en la comuna donde reside 
Artículo 339.-Esta asamblea está formada por dos miembros por departamento, todos elegidos de la misma manera que los miembros del Cuerpo legislativo y reúne las mismas condiciones exigidas por el Consejo de Ancianos.(...).

Artículo 342.-La asamblea de revisión no ejerce ninguna función legislativa ni de gobierno; se limita a la sola revisión de los artículos constitucionales que le ha designado el Cuerpo legislativo.

Artículo 343.-Todos los artículos de la Constitución, sin excepción continuian estando en vigor mientras el pueblo no acepte los cambios propuestos por la asamblea de revisión. (...).

Artículo 345.-Los ciudadanos que son miembros del Cuerpo legislativo en el momento en que se convoca una asamblea de revisión no pueden ser elegidos miembros de esta asamblea.

Artículo 346.-La asamblea de revisión dirige sin demora a las asambleas primarias el proyecto de revisión que ha decretado.

Ésta se disuelve en el momento en que se les ha enviado este proyecto.

Artículo 347.-En ningún caso la duración de la asamblea de revisión puede superar los tres meses.(...).

El tercero de los textos iniciáticos del constitucionalismo francés vuelve, con esta regulación, sus ojos al primero de ellos, hacia la Constitución de 1791. Ya desde el comienzo así se observa en ese artículo 336 que, nuevamente alude a «la experiencia» como consejera para iniciar el camino de una reforma que en todo caso sólo se entiende como parcial («algunos artículos», refiere el precepto citado, además de que el artículo 342 también lo indica). Así pues, diferenciando poder constituyente y poder de reforma constitucional, en 1795 únicamente se regula la reforma parcial de la Constitución.

En cuanto a la iniciativa, la misma nace del Consejo de Ancianos, cámara que la propone al Consejo de Quinientos para que éste la ratifique (arts. 336 y 337). Obsérvese que, si bien por un lado, al aparecer el sistema bicameral, se da protagonismo a ambas Cámaras, el proceso de iniciativa de reforma viene «intercambiado» respecto del quehacer legislativo ordinario, ya que, como antes hemos expuesto, en la tramitación legislativa el Consejo de Quinientos inicia la discusión y la aprueba mientras que el Consejo de Ancianos la ratifica. Esta es una de las escasas modificaciones procesales que se observan, y podemos decir que es debida a que, para el tema que nos ocupa, se pide precisamente a la cámara «de la razón» que sea ella la que «piense» si se debe proceder a la reforma, considerando que esta «segunda Cámara» es «en este caso» (dice literalmente el artículo 337) la primera en actuar.

En lo tocante al proceso de tramitación, a la «duración» de la iniciativa, el artículo 338, siguiendo pautas nuevamente del texto constitucional de 1791, establece el íter más complejo hasta la fecha: en nueve años, y al menos en tres oca- 
siones, se ha debido presentar por el Consejo de Ancianos al Consejo de Quinientos y esta cámara debe ratificar la propuesta de reforma constitucional. Es más, este «reenvío» intercameral debe darse con una pausa de tres en tres años, para evitar que, con una misma mayoría en las Cámaras, se puedan realizar dos acuerdos muy parejos en el tiempo ${ }^{61}$.

Respecto al órgano encargado de la revisión, hemos de aclarar que pasados estos años y cumpliendo dichos requisitos, tampoco se considera aprobada la reforma, algo que podría entenderse al haberse pronunciado ambas Cámaras en tres ocasiones durante nueve años. A continuación se convoca una asamblea de revisión (art. 338), cuya composición difiere de la propia de cualquiera de las Cámaras legislativas ordinarias, ya que el artículo siguiente prescribe que estará «formada por dos miembros por departamento» ${ }^{62}$, según el sistema electoral mediante el que se eligen ambas Cámaras ${ }^{63}$, bien que con las condiciones solicitadas para la elección del Consejo de Ancianos ${ }^{64}$.

Este órgano revisor $a d b o c^{65}$, se encuentra sometido expresamente y por vez primera a la «doctrina Sieyès» de que no puede atesorar también competencias legislativas o de gobierno ${ }^{66}$, una limitación material que queda además realzada con la previsión última que realiza este artículo 342: «se limita a la sola revisión de los artículos constitucionales que le ha designado el Cuerpo legislativo». Límite material respecto a la reforma que también amojona con claridad las competencias de cada órgano: el Legislativo ordinario goza de una iniciativa de reforma que no sólo se conforma con dar el pistoletazo de salida si no que delimita el marco material dentro del cual la asamblea revisora debe necesariamente ac-

61 Aún reconociendo que los tiempos en el siglo XIX no eran «nuestros tiempos», parece excesivo impedir que en una década a partir de que se inicie la reforma, ésta no pueda cumplirse. Y en cualquier caso, si se coronase semejante proeza, puede ser que ya fuese inoperante o, incluso, contraproducente.

${ }^{62}$ El artículo 3 indica que Francia está dividida en ochenta y siete departamentos, por lo que la asamblea revisora se compondría de ciento setenta y cuatro miembros.

63 GodechOt, op. cit., pág. 405. Vid. nota 58. Se trataba de un sistema electoral de doble grado, es decir, sufragio universal de todos los ciudadanos en las asambleas electorales (primer grado), que elegían a las asambleas primarias (segundo grado).

64 Expresa el artículo 74 de la Constitución que para ser elegido miembro del Consejo de los Quinientos se exige tener treinta años cumplidos (veinticinco hasta el séptimo año republicano), aparte de la domiciliación durante diez años antes en territorio francés. Para formar parte de la «Cámara Alta» se pedía tener cumplidos cuarenta años, ser casado o viudo y quince años de domiciliación (art. 83).

65 No hay que olvidar las previsiones referidas a la ubicación física de la asamblea de revisión respecto de la propia de las Cámaras legislativas (arts. 340 y 341): denotan una preocupación para que se aprecie con claridad que se trata de un órgano diferente al Legislador ordinario.

66 Vid. nota 19 y concordantes. 
tuar, sin poder salir del mismo, tal y como ya vimos en el texto de 1791 y se recogerá en nuestra Constitución de 1812.

Corrigiendo, para bien en este caso, lo preceptuado en la Constitución de 1791, el artículo 345 impide que todos los miembros que lo sean del Cuerpo legislativo bicameral en el momento de que se convoca asamblea revisora, puedan serlo de ésta ${ }^{67}$. Unos miembros que gozan de determinadas prerrogativas ${ }^{68}$ en una asamblea revisora a la que se le impide asistir a ceremonia pública alguna (art. 349) y que es la encargada de mantener el orden en la comuna en la que se ubica. Prerrogativas individuales y colectivas que redundan necesariamente en una independencia orgánica y funcional que se quería potenciar a la vista de los sucesos acaecidos hasta la fecha.

Además de lo anterior, el artículo 347 expresa que las tareas de reforma de la asamblea revisora no pueden durar más de tres meses, literalidad que emula a la fórmula «sin más dilación» que refería la Constitución de 1791, bien que, en este caso, nos encontramos ante un término mucho más fácilmente mensurable ${ }^{69}$.

Una vez cumplidos tanto el proceso de iniciativa, transcurridos los plazos correspondientes, constituida la asamblea revisora y cumplimentada la reforma siguiendo el proceso decisorio legislativo ordinario ${ }^{70}$, la misma no entra en vigor hasta que «el pueblo acepte los cambios propuestos» (art. 343). A mayor abundamiento, el artículo 346 indica que «la asamblea de revisión dirige sin demora a las asambleas primarias el proyecto de revisión que ha decretado», disolviéndose a continuación ${ }^{71}$. Esta llamada al pueblo como sujeto último de la soberanía no es sino un «guiño» rousseauniano, una influencia de la Constitución anterior.

${ }^{67}$ Como ya expuse (vid. nota 43) no parecía muy correcto impedir el acceso a la asamblea revisora sólo de aquellos miembros del Legislativo que estaban a favor de la reforma, como se indicaba en la Constitución de 1791.

68 Así el artículo 348 indica que no pueden ser investigados ni acusados ni juzgados por lo que hayan dicho o escrito en el ejercicio de sus funciones, sin que se les pueda juzgar por tema alguno mientras que las estén desarrollando. Por su parte el artículo 350 prevé unos honorarios para los miembros de la asamblea revisora idénticos a los emolumentos de los miembros del Cuerpo legislativo.

69 Bien es cierto que no sabemos las consecuencias de que no se cumpliese con la previsión temporal citada. Es lo que ocurre cuando se estudia cualquiera de los textos a los que nos referimos, «tótems» muchos de ellos de la Ciencia Política y del Derecho constitucional en el ámbito netamente teórico.

${ }^{70}$ Nada se dice al respecto por lo que así se deduce. Lo mismo ocurría en la Constitución de 1793, bien que en la anterior de 1791 sí que se indicaba expresamente que el procedimiento legislativo ordinario se aplicaba en el supuesto de reforma constitucional.

71 Igualmente, el artículo 26 de la Constitución establece como competencias de las asambleas primarias aceptar o no los cambios en el texto constitucional. 
Pero lo cierto es que el sistema establecido a partir de 1795 se encuentra marcado por los continuos golpes de Estado, debidos, por qué no decirlo también, a las imperfecciones jurídicas y políticas del propio texto constitucional ${ }^{72}$. Esta situación termina con el golpe de estado de 18 de brumario del año VIII (9 de noviembre de 1799), dando comienzo a la dictadura de Napoleón Bonaparte, apoyado por un Sieyès redivivo — encargado, diez años después de la Revolución, de cerrar la misma - quién, junto a Tayllerand y Fouché, serán los padres de un texto que se convertirá en la Constitución del año VIII (13 de diciembre de 1799), primer texto del periodo imperial que supone una ruptura evidente con el procedimiento rígido de reforma constitucional ${ }^{73}$.

\section{EL PROCEDIMIENTO DE REFORMA EN LA CONSTITUCIÓN DE 1812}

De manera muy breve, procedo a destacar los aspectos más generales de nuestra Constitución de 1812, tal y como avancé en el capítulo introductorio $^{74}$. Como principios básicos de nuestra Constitución gaditana ${ }^{75}$ se señalan los dimanantes del liberalismo naciente que no son otros que la soberanía nacional (art. 3, al modo y manera que el propio de la Declaración de derechos francesa), la división de poderes (arts. 15 a 17, trasuntos de los artículos 3, 4 y 5 del Título III de la Constitución de 1791), la representación nacional (arts. 27 y 100,

72 Morabito (op. cit., págs. 126-133) alude a cuestiones tan amplias como los cambios introducidos en los procedimientos electorales, en el escrutinio, o las escisiones producidas en el seno de las Cámaras, así como las limitaciones impuestas para poder resultar elegido, junto a la nueva correlación de fuerzas que se produce en el legislativo. Por ejemplo, el 30 de agosto de 1795, la Convención había decidido que las dos terceras partes de los componentes de las cámaras debían ser elegidos entre sus propios miembros, intentando perpetuar una mayoría revolucionaria en el poder; pero la renovación parcial del segundo tercio en abril de 1797 conlleva la llegada a las Cámaras de una mayoría conservadora monárquica, que observa indignada la presencia en el Directorio de los antiguos regicidas

${ }_{73}$ El texto del año VIII (1799) no hace mención alguna de procedimiento especial de reforma: se reconoce que será el Senado el órgano que deberá interpretarlo y modificarlo, previa propuesta del Primer Cónsul Así será como surja el senado-consulto de 1802 (año X) (DebBASCh, et PoNTIER, Les Constitutions... op. cit., págs. 100-101). El Texto del año XII será aprobado, para mayor gloria de Bonaparte, mediante plebiscito.

${ }^{74}$ Para una profundización sobre la Constitución de 1812 vid. Vera Santos, J. M. (2008) Las Constituciones de España. Pamplona, Thomson-Civitas, págs. 45 a 58.

75 Sigo, por todos, a TORRes Del MORAL, A. (1986) Constitucionalismo histórico español, Madrid, Atomo, págs. 39 a 44 y a FERNÁNDEZ SEGADO, F. (1986) Las Constituciones históricas españolas, Madrid, Civitas, págs. 80 a 94. 
también siguiendo el paso del texto de 1791 en su art. 2 del Título III), el principio de libertad, con la positivización de numerosos aunque deslavazados derechos, y el de una inicial igualdad (ante la ley y de códigos de los artículos 248 y 258), bien que se separe de su homónima francesa al establecer los principios de confesionalidad y de unidad religiosa (art. 12) ${ }^{76}$.

Las Cortes unicamerales («reunión de todos los diputados que representan a la Nación, nombrados por los ciudadanos», reza el artículo 27), es la institución que se regula en primer término, destacando así su posición preeminente sobre el Rey. Se componen de un diputado por cada setenta mil «almas» (arts. 31 a 33), con un mandato de dos años (art. 108, duración idéntica a la propia de la Constitución de 1791) mediante un sistema de sufragio indirecto de cuatro grados (arts. 34 a 104) ${ }^{77}$, y gozan de autonomía organizativa y funcional, mediante una absoluta separación de poderes respecto de un Monarca que, como el Rey galo en 1791, ni las convocaba ni las podía disolver, siendo incompatibles los cargos de Secretario de Despacho y diputado a Cortes (art. 95).

El Título IV de la Constitución regula al Monarca, que lo es no sólo por la gracia divina sino por la propia Constitución, lo que denota que pasa a ser un poder constituido y sometido a la misma, tal y como referimos respecto del texto de 1791. Goza de potestad legislativa compartida con las Cortes, participando en la iniciativa, sanción y promulgación ${ }^{78}$. Lo más destacado, amén de sus competen-

${ }^{76}$ Como ya indiqué, he estudiado la influencia del constitucionalismo francés, en concreto, del Texto de 1791 en la Constitución de Cádiz, en mi obra «La influencia... op. cit., págs. 143 a 162 (en las páginas 147 y 148 aludo a las diferentes posturas respecto a la misma, tema que desarrollo en Las Constituciones de España, op. cit., págs. 47 a 49). En cualquier caso remito a los artículos básicos sobre la cuestión: SEviLLA ANDRÉs, D. (1949) «La Constitución española de 1812 y la francesa de 1791»Saitabi, núm. VII, págs. 212-234; y SuÁREZ, F. (1962) «Sobre las raíces de las reformas de las Cortes de Cádiz», Revista de Estudios Políticos, núm. 126, págs. $31-67$ (47 y ss). En ellos se hace mención a trabajos de Artola, Fernández Almagro, o al primero de ellos publicado ya por Vélez en 1818 «Apología del Altar y del Trono».

77 Vid. sistema electoral de la Constitución de 1791 en nota 32. La influencia también es notoria, bien que adecuada y adaptada a la realidad española. Vid. sobre las Cortes de 1812, concretamente respecto al sistema electoral Torres del Moral, A. (2011) «Las Cortes según la Constitución de 1812», en EsCudero Lopéz, J. A. (dir.) Cortes y Constitución de Cádiz. 200 años, Madrid, Espasa, 3 vols. Vol. III, págs. 3 a 16 (5 a 7); y Fernández DomíngueZ, A. (1992), Leyes electorales españolas de diputados a Cortes en el siglo XIX. Estudio histórico y jurídico-político, Madrid, Civitas, págs. 17 a 41 .

${ }^{78}$ La primera pertenece a cualquier diputado, bien que el Rey la puede instar (arts. $171 \mathrm{y}$ 132); la sanción, por su parte, se debe dar en un plazo de treinta días, entendiendo que si no se pronuncia en ese plazo se considera sanciona la ley (arts. 142 y 145); por último puede vetar la ley durante un periodo de tres lecturas anuales, pero si éstas se dan, no necesitan la aquiescencia regia para entrar en vigor (art. 149). 
cias ejecutivas propias (art. 171), resulta ser el elenco material que el artículo 172 restringe al Monarca. Nombraba a los Secretarios de Estado y Despacho (regulados en los artículos 222 a 230), quiénes ejercían las funciones ejecutivas en nombre del Rey, asumiendo su responsabilidad mediante el refrendo, respondiendo ante las Cortes.

En 1812, Fernando VII, como en 1791 Luis XVI, queda sometido a una Constitución que se basa en la soberanía nacional, pasando a ser Rey porque así lo desea la nación, lo que conlleva el sometimiento a la norma constitucional fruto del poder soberano que ya no le pertenece ${ }^{79}$. De ahí que, salvada sea de manera muy tangencial, en ningún caso participe tampoco en el proceso de reforma constitucional como ocurre allende los Pirineos en las tres Constituciones estudiadas $^{80}$.

En cuanto al tema objeto de estudio, los constituyentes doceañistas se cuidaron muy mucho de aprobar un texto singularmente rígido, fruto de su preocupación por defender el Texto constitucional de sus enemigos potenciales ${ }^{81}$, bien que como veremos, con escaso resultado en la práctica, al igual que ocurrió en el caso francés al que antes nos hemos referido. En su Título X, dedicado a «La observancia de la Constitución y modo de proceder para hacer variaciones en ella», la Constitución gaditana recogía un procedimiento rígido de reforma ${ }^{82}$

79 Es más, podemos decir que, aunque en ningún caso se insta a acabar con una Monarquía por la que se está luchando contra el invasor francés, los liberales gaditanos temen que el mayor enemigo de su obra sea un Rey que no la acate. En otras palabras «la conciencia de estar transformado radicalmente los principios en que se basaba el régimen político anterior, de estar imponiendo, en suma, un nuevo principio de legitimidad entre los gobernantes, unido a la obviedad de que con ello se estaba violentando la voluntad del monarca, provoca, como no podía ser de otra manera, la conciencia de que será éste, el principal enemigo del régimen. Lo que, de manera necesaria, ha de traducirse en que las instituciones fundamentales del nuevo régimen hayan de ser defendidas frente al Rey» (Roura Gómez, op. cit., pág. 154). Mayor enemigo, pero no el único. Creo que sería más sencillo hacer un listado de los «defensores» de la obra hecha. Pocos, muy pocos, más allá de sus autores inmediatos.

80 Vid notas 37 y 78 .

81 Unos «enemigos» que incluso podían encontrarse entre los componentes de las Cortes constituyentes. Vid. sobre el diferente posicionamiento habido respecto al propio procedimiento de reforma establecido CALZADA CONDE, R. (1989) «El principio configurador y garantista de la Constitución de Cádiz», en VV.AA., Materiales para el estudio de la Constitución de 1812, Madrid, Tecnos, págs. 141-148 [157-160]. Al finalizar el Discurso Preliminar se advertía el temor de los constituyentes: «La ignorancia, el error y la malicia alzarán el grito contra este proyecto. Le calificarán de novador, de peligroso, de contrario a los intereses de la Nación y derechos del Rey (...)». Pocos amigos, muchos enemigos. La ecuación era evidentemente peligrosísima.

82 Rigidez que destacaba «el deseo de los autores de la Constitución de dar estabilidad y duración a su obra; de impedir modificaciones apresuradas, de evitar entre nosotros la inestabilidad 
que a continuación, después de observar su literalidad, procederemos a diseccionar $^{83}$ :

(...) Art. 375.-Hasta pasados ocho años después de hallarse puesta en práctica la Constitución en todas sus partes, no se podrá posponer alteración, adición ni reforma en ninguno de sus artículos.

Art. 376.-Para hacer cualquier alteración, adición o reforma en la Constitución será necesario que la Diputación que haya de decretarla definitivamente venga autorizada con poderes especiales para este objeto.

Art. 377.-Cualquiera proposición de reforma en algún artículo de la Constitución deberá hacerse por escrito, y ser apoyada y firmada a lo menos por veinte diputados.

Art. 378.-La proposición de reforma se leerá por tres veces con el intervalo de seis días de una a otra lectura; y después de la tercera se deliberará si ha lugar a admitirla a discusión.

Art. 379.-Admitida la discusión, se procederá en ella bajo las mismas formalidades y trámites que se prescriben para la formación de las leyes, después de los cuales se propondrá la votación, y si ha lugar a tratarse de nuevo en la siguiente diputación general; y para que asi quede declarado, deberán convenir las dos terceras partes de los votos.

Art. 380.-La Diputación general siguiente, previas las mismas formalidades en todas sus partes, podrá declarar en cualquiera de los dos años de sus sesiones, conviniendo en ello las dos terceras partes de los votos, que ha lugar al otorgamiento de poderes especiales para hacer la reforma.

Art. 381.-Hecha esta declaración, se publicará y comunicará a todas las provincias; y según el tiempo en que bubiere hecho, determinarán las Cortes si ha de ser la Diputación próximamente inmediata o la siguiente a ésta, la que ha de traer los poderes especiales.

Art. 382.-Éstos serán otorgados por las juntas electorales de provincia, añadiendo a los poderes ordinarios la cláusula siguiente:

"Asimismo les otorgan poder especial para hacer en la Constitución la reforma de que trata el decreto de las Cortes, cuyo tenor es el siguiente: (aqui el decreto literal). Todo con arreglo a lo prevenido por la misma Constitución. Y se obligan a reconocer y tener por constitucional lo que en su virtud establecieren».

\footnotetext{
constitucional que ya entonces se registraba en otros países» (VilLarroya, J. T. (1994) Breve historia del constitucionalismo español, Madrid, Centro de Estudios Constitucionales, pág. 14).

${ }^{83}$ Los primeros artículos comprendidos en este Título destacan otras cuestiones relacionadas más con «la observancia de la Constitución» que con «el modo de proceder para hacer variaciones en ella». Así: Art. 372. Las Cortes en sus primeras sesiones tomarán en consideración las infracciones de la Constitución, que se les bubieren hecho presentes, para poner el conveniente remedio y hacer efectiva la responsabilidad de los que bubieren contravenido a ella. Art. 373. Todo español tiene derecho a representar a las Cortes o al Rey para reclamar la observancia de la Constitución. Art. 374. Toda persona que ejerza cargo público, civil, militar o eclesiástico, prestará juramento, al tomar posesión de su destino, de guardar la Constitución, ser fiel al Rey y desempeñar debidamente su cargo.
} 
Art. 383.-La reforma propuesta se discutirá de nuevo; y si fuere aprobada por las dos terceras partes de diputados, pasará a ser ley constitucional, y como tal se publicará en las Cortes.

Art. 384.-Una Diputación presentará el decreto de reforma al Rey, para que le haga publicar y circular a todas las autoridades y pueblos de la Monarquía.

El artículo 377, por un lado, excluye la reforma total, tal y como ocurría en los casos de las Constituciones de 1791 y $1795^{84}$. En segundo lugar, refleja que dicha reforma del articulado constitucional se inicia a través de la presentación por escrito y con la firma y apoyo de veinte diputados ${ }^{85}$. Con esta medida se pone de manifiesto el intento de evitar la presentación aleatoria de reformas constitucionales que no tuvieran visos de poderse aprobar, produciendo «ruido en el sistema».

En cuanto al procedimiento de reforma hay que destacar también dos aspectos: las tres lecturas y la mayoría cualificada. El artículo 378, efectivamente alude a que la propuesta de reforma debe leerse en la Cámara en tres ocasiones, dejando pasar al menos seis días entre lectura y lectura ${ }^{86}$, decidiéndose su admisión o no. Toda vez aprobada, se va a discutir siguiendo el procedimiento ordinario (así lo indica expresamente el artículo 379); eso sí, para que la propuesta sea tratada por una segunda Cámara el acuerdo debe adoptarse por mayoría de dos terceras partes de los votos, mayoría cualificada que supone un plus respecto a la formación ordinaria de la $l e y^{87}$ y que proviene, en este caso, de la Constitución norteamericana.

De la literalidad de los preceptos citados se observa que, hasta ahora, hemos aludido a una primera diputación/legislatura, que discute mediante tres lecturas la iniciativa que presentan al menos veinte diputados y que se adopta como tal según las prescripciones que regulan el procedimiento legislativo ordinario, excepto cuando debe aprobarse su paso a una nueva diputación, acuerdo que se adopta por la mayoría cualificada antes dicha.

Esta segunda diputación, reza el artículo 380, a lo largo de sus dos años de mandato, debe aprobar por idéntica mayoría, que se otorguen los correspon-

84 El artículo 375 también incide en esa idea al aludir a «ninguno de sus artículos». Queda excluida por tanto en la teoría y en la práctica, la posible reforma total de la Constitución.

85 Hay que recordar que el artículo 132 de la Constitución establecía que la iniciativa legislativa ordinaria correspondía a cada diputado.

${ }^{86} \mathrm{El}$ procedimiento ordinario también se basa en las tres lecturas, bien que con una diferencia temporal entre ellas menor, pero tampoco nos parece en exceso significativo. Vid. al respecto los artículos 133 y siguientes, en los que se recoge el proceso de formación de las leyes y la sanción regia.

87 El artículo 139, respecto del procedimiento ordinario de formación de las leyes pide una mayoría simple y un quórum de presencia de la mitad más uno de los diputados. 
dientes "poderes especiales para hacer la reforma» ${ }^{88}$. Unos poderes especiales que son otorgados por las Juntas electorales de cada provincia, añadiendo a los poderes ordinarios, la posibilidad de reformar la Constitución en aquellos aspectos que refleje el decreto de estas segundas Cortes que deciden continuar con el proceso (art. 382).

Observamos, pues, dos cuestiones. La primera: se intenta que los electores y los propios elegidos sean conscientes de que no se trata de una legislatura más, de una diputación ordinaria. De ahí que el artículo 381 exija que, una vez que se decida por la segunda diputación que continúe el procedimiento y que se expidan poderes especiales, extraordinarios, se comunique de inmediato a todas las provincias. Es más, y esta cuestión es relevante, dependiendo del momento, del «tiempo» en el que la segunda diputación haya aprobado que se soliciten tales poderes, ella misma va a decidir si elos elegidos para la siguiente diputación (sería, para entendernos, la tercera) o la siguiente a ésta (una cuarta) traerían esos poderes especiales ${ }^{89}$. Por tanto, teóricamente no podemos hablar de que sean tres diputaciones/legislaturas/de manera continua (es decir, en seis años) las que decidan sobre la reforma. Son tres legislaturas diferentes, sí; pero pudiera ser que, entre la segunda y la que decida finalmente, aparezca una tercera que no goza de poderes de reforma. Lo que quiere decir que el proceso, para completarse, sí requiere or-

88 De esos mismos poderes especiales habla Sieyès cuando alude a ese «cuerpo de representantes extraordinarios» que asumen la soberanía, como leemos en la nota 22.

89 Se quiere evitar que la segunda diputación, poco antes de concluir su mandato y por sorpresa, decida solicitar poderes de reforma para los electos de la siguiente diputación, hurtando a los ciudadanos un reposado conocimiento de que se estuviese preparando una reforma constitucional. En fin, utopía sobre utopía... Los ciudadanos demostraron con rapidez que la Constitución les importaba muy poco. Es más, se posicionaron en su contra sin mayores dudas. Esa es la realidad, guste o no. Incluso cuando se festeja su segundo centenario, habrá que decir que el pueblo español nunca vio con buenos ojos esta Constitución. Y es que, podemos aseverar que «pocos años después de su promulgación ya no interesa ni a sus mismos autores» (SEVILlA ANDrÉs, D. (1962) «La Constitución de Cádiz, obra de transición», Revista de Estudios Políticos, núm. 126, págs. 113-141). «(...) hay que reconocerlo, en la época en que se dio resultó obra de una minoría, todo lo valiosa y todo lo ilustrada que se quiera, pero al fin una minoría. La opinión general, ni pensaba como los autores de la Constitución, ni estaba preparada para recibir tan gran mudanza (...)» (BÉCQUER, J. (1923) La reforma constitucional en España, Madrid, J. Ratés Martín, págs. 4041). Una Constitución, no obstante, cuya influencia teórica está fuera de dudas desde el punto de vista doctrinal que no tanto en la práctica constitucional española. Identificar constitucionalmente (no niego un ropaje teórico que se inicie en el liberalismo radical gaditano) el texto de 1812 con la Constitución de 1869, el proyecto de 1873 o la también demasiado alabada Constitución de 1931, creo que no es del todo adecuado. Influencia teórica sí; concatenación institucional, no tanta (vid. VArela SuAnZes-Carpegna, op. cit., págs. 107-108) Respecto a su influencia internacional vid. nota 96. 
gánicamente de tres legislaturas, pero no necesariamente seguidas, pudiendo alargarse el proceso hasta los ocho años ${ }^{90}$.

En segundo término, nuestro texto gaditano aúna los poderes especiales de reforma y los ordinarios, en contra de lo preconizado por Sieyès. Es decir, que esa cronológicamente tercera o cuarta diputación, tendría capacidades normativas ordinarias y de reforma constitucional ${ }^{91}$.

Esta legislatura ordinaria, encargada de revisar la Constitución, discutirá de nuevo la reforma propuesta, estando limitada a hacerlo sobre las cuestiones que la anterior legislatura le indicase ${ }^{92}$ (art. 383). Si se aprobase la reforma por mayoría de dos tercios de diputados quedará aprobada, no pudiendo el Rey vetarla $(\text { art. 384 })^{93}$, ni tampoco necesita de referéndum alguno para su vigencia.

Antes de concluir con el complejo proceso que señala la Constitución de Cádiz, no puede obviarse la cláusula temporal que «abría» los artículos reguladores de la reforma constitucional. El artículo 375 indicaba que, para proponer, alterar, adicionar o reformar algún artículo, debían pasar al menos ocho años desde que se pusieran en práctica todas las partes de la Constitución. La motivación se indicó sin tapujos: posibilitar el mantenimiento de la Constitución y de sus principios para lograr estabilidad institucional y política, amén del apoyo popular al nuevo sistema basado en la soberanía nacional, la separación de poderes, el reconocimiento de derechos... ${ }^{94}$. Ocho años que no eran tales: se contaban después de

90 Este matiz supone una diferencia con el sistema que regía en la Constitución de 1791, haciéndolo aún más rígido, si bien es cierto que aquel aludía a una «cuarta legislatura» que era la que se constituía en órgano revisor y, por ende, decisor. Reiterar nuevamente mi opinión sobre la necesaria vinculación de los acuerdos habidos respecto a la reforma en las anteriores diputaciones y su vinculación con la decisión final, tal y como ya expusimos al referirnos a la Constitución francesa de 1791 (vid. nota 38). Sigo al respecto, con algún matiz, a Amérigo Alonso, J. y Jeréz CaldeRÓN, J. J. (2006) «El procedimiento de revisión constitucional en dos legislaturas: un análisis comparado e histórico», Revista Española de Derecho Constitucional, núm. 76, págs. 179-200 (concretamente págs. 189 y ss.).

91 Como ocurría en los casos de los textos franceses de 1791 y 1793.

92 Refleja Fernández Segado, op. cit., págs. 172 y 173, que en Cádiz se desconoce el concepto de asamblea constituyente como órgano diferente al legislativo ordinario, tal y como ocurría en la Francia de los textos de 1791, 1793 y 1795, bien que cada uno «a su manera» (Cuerpo legislativo más doscientos cuarenta y nueve miembros más, Convención nacional y dos representantes por departamento).

93 Como ocurre en el caso francés, el Monarca queda excluido de todo el procedimiento, pues no se le reconocía ni la facultad de sanción/veto ni tampoco la de iniciativa. Sí tenía una, digamos «iniciativa indirecta» al igual que respecto a la ley ordinaria, bien que el artículo 171 incluía como facultad del Rey «hacer a las Cortes las propuestas de leyes o de reformas, que crea conducentes al bien de la Nación (...)». Vid. notas 37 y 80.

94 Pérez Royo, J., La reforma, op. cit., págs. 53 y 54. En el Discurso Preliminar se puede leer: 
la entrada en vigor de la Constitución en todas sus partes, concepto jurídico y político muy indeterminado. $\mathrm{Al}$ menos ocho años, diríamos, desde su entrada en vigor, pero, interpretables por esa cláusula a la que nos referimos.

Como en los casos relatados de Francia, estas disquisiciones sobre el proceso de reforma, no dejan de ser eso, elucubraciones. Recuérdese la tan manida frase de Gautier respecto a la identificación en España de la Constitución y, lamentablemente, del sentimiento constitucional, con aquella lápida pegada con cemento al granito, una lápida de «quita y pon» sobre una realidad diferente ${ }^{95}$.

\section{CONCLUSIONES}

Como advertí en la introducción, una vez que hemos observado las características de las génesis constitucionales en los sistemas norteamericano y francés, así como la regulación de la rigidez constitucional en cada una de ellas, conviene destacar la influencia ejercida sobre el constituyente gaditano, objeto final de este estudio. Pasemos así «de las musas al teatro»:

A. El reflejo del modelo norteamericano en nuestro texto de 1812 queda muy diluido. Bicameralismo, federalismo, soberanía popular, inexistencia de una teoría y realidad absolutista con un Rey al que «embridar», sustituidas, creo yo, por ciertos temores de que el Estado federal se «leviatanizara» (de ahí el excesivo peso de los Estados federados en el proceso de reforma), son consideraciones que, más que la distancia física, alejan la obra americana, en vigor desde 1787 , de nuestras costas sureñas. Sí puede observarse cierta correlación en la solicitud de mayorías cualificadas para adoptar los acuerdos atinentes a la reforma constitucional. Me

\footnotetext{
«El que pasados ochos años después de puesta en ejecución en todas sus partes, no puedan las Cortes proponer ninguna reforma, tiene su fundamento en la prudencia y en el conocimiento del corazón humano. Jamás correrá mayor riesgo la Constitución que desde el momento en que se anuncie, hasta que planteado el sistema que establece, empiece a consolidarse disminuyendo el espíritu de aversión y repugnancia que la contradice. Los resentimientos, las venganzas, las preocupaciones, los diversos intereses y hasta el hábito y la costumbre, todo se conjugará contra ella. Por lo mismo es necesario dar tiempo a que se calme la agitación de las pasiones, y se debiliten los esfuerzos de los que la resisten» (SEviLLA ANDRÉs, D. (1969) Constituciones y otras leyes y proyectos politicos de España, t. I, Madrid, Editora nacional, pág. 159). Un poco antes se refiere «a la experiencia» como «única autoridad» que iluminaría la reforma constitucional, trayendo a colación esta expresión que ya hemos observado en el constituyente francés de 1791 y 1795 . De «piedra angular de la Constitución» habla Argüelles al referirse a este artículo (Discursos.... op. cit., págs. LXI y 261).

95 Sobre la procelosa vida política y sus diferentes avatares, desde luego nunca marcados por este procedimiento de reforma expuesto, vid. Vera Santos, Las Constituciones de España, op. cit., págs. 46 y 56 a 59 .
} 
refiero a los dos tercios que refleja el artículo V de la Constitución norteamericana, mayoría que también se recoge en el articulado gaditano. También, como veremos más adelante, pudiera observarse correlación entre las limitaciones temporales para la reforma existentes tanto en aquél como en nuestro propio texto.

B. Otro gallo nos canta si recalamos en el constitucionalismo del otro lado de los Pirineos. Esa cercanía geográfica (corregida y aumentada por una simultánea invasión militar), simboliza también la influencia francesa, teórica y práctica, en nuestro texto constitucional. Se quiera o no ver, las ideas y el texto francés de 1791 gozan de tal ascendiente sobre la Constitución de 1812 que, como he defendido en obras anteriores, se concreta en un «importante paralelismo axiológico, institucional y normativo» ${ }^{96}$. Y es que, si estudiamos los principios políticos, la plasmación de derechos y libertades, la soberanía nacional, la separación de poderes, la diferenciación del poder constituyente y su obra respecto de unos poderes constituidos, limitados competencialmente, entre los que se encuentra el Monarca o el mandato representativo, no son sino ejemplos de lo dicho. Lo mismo ocurre en el ámbito institucional en el que se plasma la anterior axiología: poderes legislativo, ejecutivo y judicial, sistemas electorales de diferentes grados, recepción constitucional de derechos... o el establecimiento de un sistema rígido de reforma que garantizase la defensa política de una Constitución que acababa de romper con el antiguo régimen absolutista.

Entrando ya en el tercero de los paralelismos, el normativo, corresponde efectivamente, destacar si existe, o no, en el procedimiento de reforma constitucional. Voy a ello.

B.1. En cuanto al ámbito material de la reforma, en ninguno de ambos textos se regula la reforma total. Es decir, se considera objeto de regulación la reforma parcial, diferenciando con ello el cambio «en»

96 Así lo destaco en «La influencia del constitucionalismo...», op. cit., págs. 147, 148 y 176. Como ha quedado reflejado antes, el modelo de 1791 también sirve de inspiración a los constituyentes de 1795, bien que me parece evidente la mayor identidad del primero de los textos con la Constitución española de 1812. La Constitución de 1793 supone un sistema diferente a los citados, aunque contenga prescripciones concretas coincidentes: así las limitaciones materiales o la permisión de que se aúnen poderes de reforma y legislativos ordinarios. Dicho lo cual, no podemos dejar de destacar que, si bien la gaditana «plagia, en parte» a la de 1791 (DE EsteBAN, J. «La Constitución de Cádiz y su imposible reforma», en EsCUDERO LÓPEZ..., op. cit., vol. III, págs. 413 a 426 [423]), posteriormente influye más que el original en el primer liberalismo europeo. Muy acertados los artículos a este respecto que aparecen en dicha obra a partir de la página 459 de su volumen tercero, respecto a la proyección internacional de la Constitución de Cádiz, tanto en Europa como en América. 
la Constitución, obra del poder constituido de reforma constitucional, del cambio «de» Constitución, fruto de un poder constituyente ilimitado y metajurídico.

B.2. La Constitución de Cádiz permite, al modo del texto de 1791, que se aúnen en un sólo órgano los poderes de reforma constitucional y los ordinarios legislativos. En el caso español es evidente; en el primero de los textos franceses los miembros «especiales» nombrados con ocasión de proceder a la reforma no pueden deliberar sobre legislación ordinaria, debiendo retirarse toda vez que se haya procedido al acuerdo de reforma «sin mayor dilación», es decir a la mayor brevedad posible en cuanto se constituyese el Cuerpo Legislativo como órgano decisor.

B.3. La iniciativa de reforma constitucional recae sobre los hombros del legislador ordinario. En el caso de 1812, ya sabemos que eleva la iniciativa de reforma respecto de la legislativa ordinaria, pasando de uno a veinte diputados. Se advierte una similitud en el proceso de adopción del acuerdo de reforma: se pide la aquiescencia de tres legislaturas consecutivas en el caso de 1791; en Cádiz también se necesita la aprobación por tres legislaturas, bien que pueden ser no consecutivas, dependiendo del «tiempo» en que hubiese acordado la segunda diputación la solicitud de poderes especiales. Si «temporalizamos» el proceso, en 1791 con seis años transcurridos se da paso a que el órgano revisor que se crea decida «con la máxima rapidez»; la Constitución de Cádiz, por su parte, posibilita que: a) si las tres diputaciones son consecutivas se pueda reformar la Constitución antes de seis años; b) si no son consecutivas, se tendrían que utilizar entre seis y ocho años, partiendo de que, como en el caso de la Constitución de 1791, el mandato de la asamblea es de dos años. Me remito a lo ya expuesto sobre la «uniformidad» que se pide en los diferentes acuerdos de tramitación respecto a los aspectos a reformar hasta su aprobación definitiva, bien por una nueva diputación (la tercera o la cuarta, en el caso gaditano), bien por un órgano ad hoc en el caso francés.

B.4. Como antes he manifestado, no corren parejos los casos franceses y el español precisamente en la creación o no de un órgano revisor diferente del legislador ordinario. Cádiz opta por que decida el propio órgano legislativo, siguiendo el mismo procedimiento ordinario, exceptuando, como he dicho, el incremento de la mayoría solicitada. En 1791 se incorporan más miembros específicamente para tratar la reforma en ciernes. 
B.5. La utilización del procedimiento legislativo ordinario para la tramitación de la reforma, también une a los textos de 1791 y de 1812. Igualmente se aboga por un modelo de tres lecturas en ambos casos. Las excepciones a este procedimiento aparecen como muy tasadas y escasas no sólo en estas Constituciones sino en las otras estudiadas. Transcurrirán siglos hasta que las modificaciones procesales y de incremento de las mayorías cobren protagonismo. Eso ocurre, en nuestro caso, con la solicitud de una mayoría cualificada para la toma de decisiones en el procedimiento de reforma, algo que no ocurre en la Constitución de 1791 (tampoco en las otras dos Constituciones francesas estudiadas), pero sí en el texto constitucional norteamericano.

B.6. La limitación temporal referida a los ocho años después de la entrada en vigor de la Constitución en todas sus partes, parece acercarse más a la prescripción del artículo V de la Constitución americana de 1787: me refiero, claro está, no a la cláusula de intangibilidad, sino a la prohibición explícita de reformar hasta 1808, eso sí, sólo determinadas materias tasadas. Se asemejan más los principios y la finalidad buscada en estos casos que los preceptos existentes en el constitucionalismo francés, mucho más preocupado por que las tareas de reforma se realizasen, toda vez constituidos los órganos de revisión, «sin mayor dilación», leemos en la Constitución de 1791 o en un plazo máximo de tres meses (1795).

B.7. No existe mención alguna, ni en 1791 ni en 1812 a que se necesite la ratificación popular de la reforma decidida, olvidando los ejemplos franceses de 1793 y 1795. Tampoco se alude al Monarca como actor en la misma.

C. Respecto a las Constituciones francesas de 1793 y 1795 resulta más sencillo y honesto remitirme a lo expuesto: las coincidencias del texto gaditano con ésta última son mayores, pero no tan abundantes como en el caso observado de 1791. El modelo rousseauniano de 1793 aparece más lejano, independientemente de que podamos destacar sus semejanzas: monocameralismo, uso para la reforma del procedimiento legislativo ordinario o la unión en el órgano revisor del poder de reforma y el ordinario legislativo.

Concluyo, muy brevemente. No se puede negar la evidencia. En el propio Discurso Preliminar ya se intentó... y no «coló». La circunstancia orteguiana del momento era francesa; más concretamente fechada en 1791. Y nuestra Consti- 
tución gaditana se vio netamente influenciada por el primer texto constitucional revolucionario: sus principios, sus instituciones... Y el procedimiento de reforma de la Constitución, con los correspondientes matices antes meritados, no fue una excepción.

Title:

NORTH AMERICAN AND FRENCH PRECEDENTS AND THEIR INFLUENCE ON THE CONSTITUTIONAL RIGIDITY OF THE SPANISH CONSTITUTION OF 1812

\section{Summary:}

INTRODUCTION. 1. CONSTITUTIONAL RIGIDITY IN THE CONSTITUTION OF THE UNITED STATES OF AMERICA OF 1787. 2. CONSTITUTIONAL RIGIDITY IN REVOLUTIONARY FRENCH CONSTITUTIONALISM. 2.1. The Constitution of 1791. 2.2. The Constitution of 1793. 2.3. The Constitution of 1795. 3. THE PROCEDURE OF REFORM OF THE CONSTITUTION OF 1812. CONCLUSIONS

\section{Resumen:}

El autor analiza en este artículo la influencia de la Constitución norteamericana de 1787 y de las tres Constituciones revolucionarias francesas $(1791,1793$ y 1795) en la regulación que de la reforma constitucional prescribe el texto constitucional español de 1812.

Dejando al margen matices, llega a la conclusión de que a) la influencia francesa es mucho más elevada que la de los constituyentes de Filadelfia; b) que la Constitución francesa de 1791 influye decisivamente en el texto gaditano en los ámbitos axiológico, institucional y normativo; c) que la Constitución rosusseauniana de 1793 no sirve de modelo a nuestros liberales gaditanos, más propensos al pensamiento de Sieyès; d) que la Constitución francesa de 1795 asume los postulados de la de $1791 \mathrm{y}$, por ende, pueden observarse ciertos paralelismos indirectos con la española de 1812.

En lo concreto, la asunción de una iniciativa de reforma que debe aprobarse por tres legislaturas, siguiendo salvo excepciones el procedimiento fijado para la formación de la voluntad legislativa ordinaria; la concreción de la misma únicamente a la reforma parcial, no admitiendo la revisión total; la posible unión en el órgano revisor de poderes ordinarios y los propios de reforma, o la inexistencia de aprobación posterior por el pueblo llamado en referéndum, así como la exclusión del antes todopoderoso Monarca de todo el proceso de reforma, con- 
forman una realidad difícil de negar: la Constitución de 1791 fue tenida como libro de cabecera por los redactores de la Constitución española de 1812 .

\section{Abstract:}

In this article the author analyses the influence of the Constitution of the United States of 1787 and the three French revolutionary constitutions (1791, 1793 and 1795) on the regulation of constitutional reform set forth in the Spanish Constitution of 1812.

Certain details aside, the author concludes that a) the French influence is much greater than that of the Philadelphia Constitutional Convention; b) the French Constitution of 1791 exerts a decisive influence on axiological, institutional and normative aspects; c) the Rousseaunian Constitution of 1793 does not serve as a model for our liberals from Cadiz, who were more inclined towards Sieyès' thought; d) the French Constitution of 1795 adopts the postulates of the Constitution of 1791 and, consequently, certain indirect parallelisms with the Spanish Constitution of 1812 can be observed.

Thus, the parallelisms between the Constitution of Cadiz of 1812 and the French Constitution of 1791 are evident: the exclusive regulation of partial reform, excluding total revision of the Constitution; the acceptance of an initiative of reform that should be approved by three legislatures following, with a few exceptions, the procedure laid down for the formation of ordinary legislative will; the possible union of ordinary powers and those specific to the reform in the revising authority, or the inexistence of subsequent approval by the people called to a referendum, as well as the exclusion of the all-powerful Monarch from the entire process of reform, make up a reality hard to deny: the Constitution of 1791 exercises a powerful influence over the authors of the Spanish Constitution of 1812.

\section{Palabras clave:}

Constitución española de 1812, reforma constitucional, influencias constitucionales francesas y norteamericanas.

\section{Key words:}

Spanish constitution of 1812, constitutional reform, french and american constitutional influences. 